\title{
AKIRA: arma de destrucción masiva
}

\section{Antonio Sánchez Cabrera}

Antonio Sánchez Cabrera (1979), licenciado en Historia del Arte en la Universidad de Granada. Máster de Tutela y conocimiento del patrimonio histórico enfocado a estudios de investigación en la misma universidad. Grabador y especialista en técnicas de estampación, Escuela de Artes y Oficios de Granada. Realizó su trabajo de investigación (TFM) bajo el título "Akira y la visión de lo apocalíptico en el manga japonés" del que extrae el siguiente estudio.

A Salvador y a Carmen, descubridores del otro lado de los Boliches.

Fecha de recepción: 6 de noviembre de 2015

Fecha de aceptación definitiva: 3 de diciembre de 2015 


\title{
Resumen
}

El género apocalíptico en el que se enmarca la obra de Akira engloba todas aquellas situaciones con un carácter catastrófico y devastador, pero la palabra apocalipsis originalmente tuvo un significado de revelación. En la historia de Akira, su autor, Katsuhiro Ôtomo, nos muestra ambos significados de esa palabra. Por un lado Akira es una obra distópica y catastrófica, y por otro lado hay un paralelismo histórico con lo que ocurrió durante la segunda guerra mundial que subyace durante su lectura en cuanto al armamento militar se refiere, así como a la experimentación biológica con humanos con fines bélicos. En este artículo se pretende dar unas pinceladas de ese apocalipsis historicista.

Palabras clave: Akira, Katsuhiro Ôtomo, historia militar, armamento, manga

\begin{abstract}
Akira's apocalyptic genre, includes all those catastrophic and devastating situations, although the Word apocalypse had originally the meaning of revelation. In Akira's storyline, its autor, Katsuhiro Ôtomo, shows us both meanings of the Word. On the one hand Akira is anti-utopian and disastrous, on the other hand it draws a historical similarity with facts from World War II concerning military aspects, as well as biological experiments for war purposes. In this article, we try to uncover this historical apocalypse in its story.
\end{abstract}

Key words: Akira, Katsuhiro Ôtomo, Military History, weapons, manga

\section{Cita Bibliográfica}

Sánchez Cabrera, A. "AKIRA: Arma de destrucción masiva", en CuCo, Cuadernos de cómic n. ${ }^{\circ} 5$ (2015), pp. 25-53 


\section{Introducción}

Akira (1982-1990) es una historia de ficción distópica que se encuentra muy cerca de los hechos reales ocurridos en los estados de guerra, siendo este tema el núcleo duro de la narración. Es una historia de ficción en tanto que encontramos elementos que no reconocemos en nuestro día a día como los niños con poderes telequinésicos que aún conociendo y teniendo noticias de algunos de estos casos, ${ }^{1}$ podríamos decir que se salen de lo común y no forman parte de la cotidianidad. También, el entorno marca la diferencia, la arquitectura que utiliza Katsuhiro Ôtomo en Akira proveniente de lo que se ha llamado el Cyberpuk desde los años 80 , y que no es otra cosa que la sordidez y la frialdad de un urbanismo ajeno a lo pedagógico, solo accesible a personajes nocturnos y abyectos, resignados en cualquier caso a una jungla de hormigón inaccesible y sombría, y otro tanto podríamos decir de la maquinaria tecnológicamente avanzada que hace las veces de elemento disuasorio muy propio para una época alborotada socialmente donde las explicaciones sobran y lo único importante es la aplicación del orden bajo cualquier situación. A todo ello hay que sumar el estilo narrativo, acuciante de Katsuhiro Ôtomo que se asemeja demasiado a lo que consideramos ficción y finalmente lo que quizás marca más la diferencia con la realidad sea el hecho de que la novela es gráfica, es decir que tenemos que enfrentar nuestra cultura occidental y adulta tan poco afín (hasta ahora) a creerse una historia contada a través de unos trazos ligeros como son los dibujo manga. Estos factores, unidos también a un guión que apoya la narrativa gráfica, hacen que rápidamente asociemos la historia que estamos leyendo y viendo a un drama de ficción. El problema radica en que la historia de Akira es excesivamente parecida a la realidad histórica. En este artículo trataremos de manifestar en clave histórica lo que el autor pone en clave de novela gráfica con respecto al armamento militar que se usa en el manga.

\section{Armas}

La historia del armamento está bien documentada y no ha dejado de crecer hasta el punto de que se ha tenido que poner límites a una carrera que parecía no tener fin. Estos límites versan en torno al "sufrimiento innecesario". Se produce cuando el combatiente ha sido ya retirado del campo de batalla y sin embargo continúa sufriendo las heridas de guerra, por lo que se ha tenido que definir y diferenciar entre ambos sufrimientos, es decir que se entiende que una vez retirado el soldado este ya no causará más daño al enemigo y no hay necesidad

${ }^{1} \mathrm{La}$ telequinesis y los fenómenos paranormales no son aceptados por la Comunidad científica, en España el caso más célebre es el de Uri Geller (Tel Avid, 1946), famoso por doblar cucharas. Pero hay otros como la española Mónica Nieto Tejada (Cáceres, 1972). En el ámbito internacional fueron reconocidos el Grupo Rhine y personas como Nina Sergejevna Kulagina (Leningrado, 1926-1990). 
por tanto de un sufrimiento de posguerra. Una de las primeras potencias en advertirlo fue Rusia en una fecha tan temprana como 1860 cuando el ejército había creado una bala que hacía explosión en el cuerpo del soldado ${ }^{2}$. En 1868 se convocó en San Petersburgo una conferencia internacional para debatir estos asuntos ya que el zar no estaba dispuesto a dejar de usar un arma nueva si el enemigo la seguía utilizando. Aquel acto se conoció como la Declaración de San Petersburgo y fue seguido por otros hitos similares donde se abordaba dicha cuestión: 1899 en La Haya, 1907 en los Países Bajos o 1949 en Ginebra. Este último destaca por varias razones. El Derecho Internacional Humanitario (DIH) cuenta con una serie de instrumentos como es el Convenio de Ginebra de 1949, que consta de cuatro tratados internacionales a los que se le adhieren tres Protocolos de carácter humanitario. Esta idea partió de Henry Durant, empresario suizo que tras contemplar los desastres de-

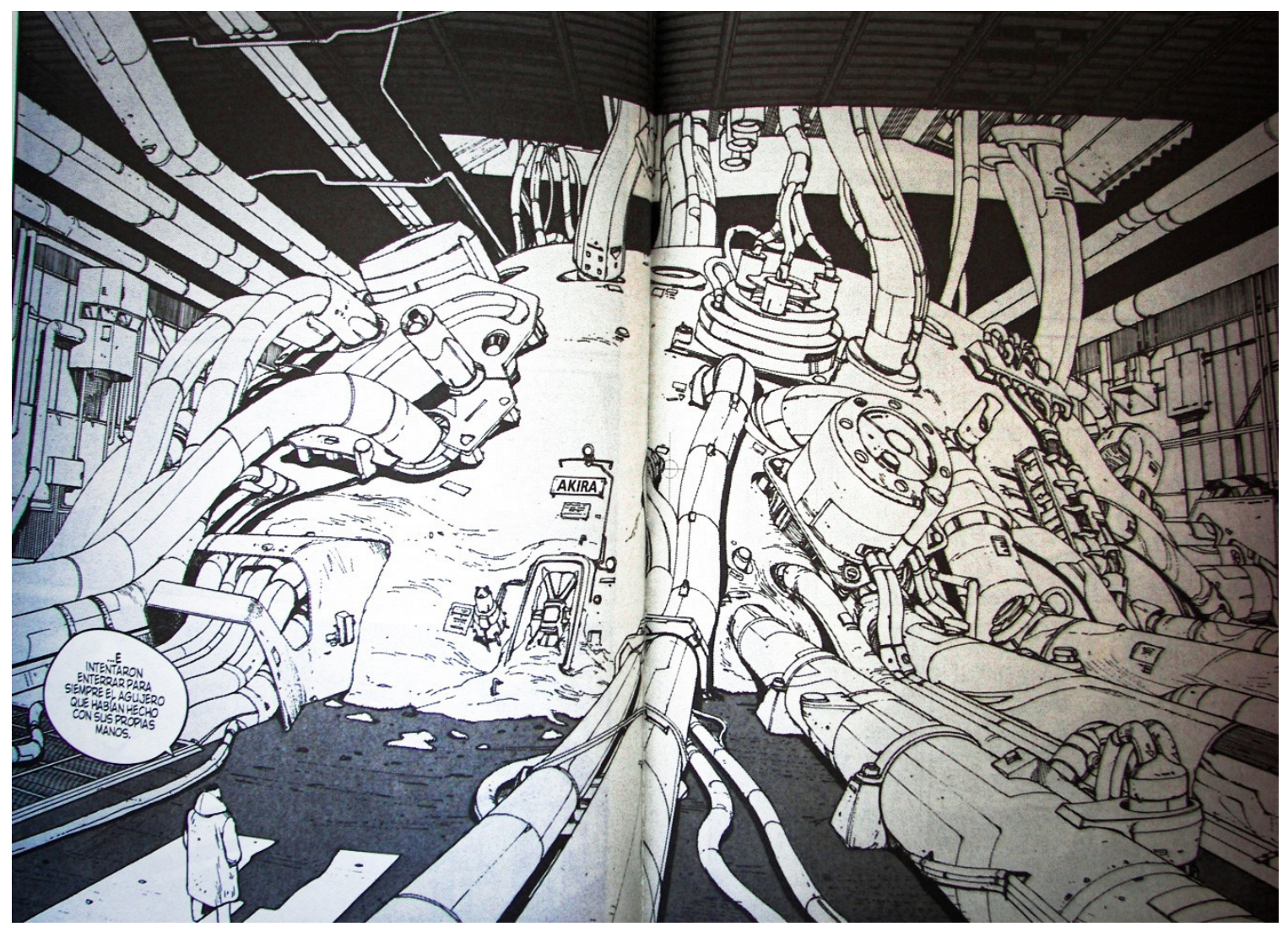

FIG. 1. Ôтомо, K. Akira. Barcelona, Ediciones

B, 1999, vol. 1.', p. 216.

rivados de la guerra franco-suiza de 1859 construye lo que se llamó el "Comité de los Cinco" que pronto derivó en la Cruz Roja, cuyo emblema es la bandera de Suiza con los colores invertidos. Los convenios son cuatro: 1) los relacionados con los ejércitos en campaña, 2) los ejércitos en el mar, 3) el trato a los prisioneros y 4) el trato a los civiles. Por otro lado se puso de manifiesto la necesidad de un distintivo neutral en caso de conflicto por lo que se eligió la cruz roja sobre fondo blanco, al que luego se adhirió la media luna roja y el llamado

${ }^{2}$ Gutman, R. y Rieff, D. Crimenes de Guerra, lo que debemos saber. Barcelona, Debate, 2003. 
Cristal Rojo, símbolo incorporado en 2005 cuyas connotaciones religiosas son nulas. También se ha aceptado la Estrella de David Roja en el caso israelí. ${ }^{3}$

En el tomo primero de Akira (pag. 216) el coronel baja por vez primera a las profundidades donde Akira permanece encerrado y comenta para sus adentros:

¡Qué desgracia! Tenían miedo, estaban asustados... decidieron ocultarlo... decidieron enterrar las raíces de una gran civilización... volvieron la espalda a lo que la ciencia les ofrecía... e intentaron enterrar para siempre el agujero que habían hecho con sus propias manos.

La viñeta que ocupa dos páginas ofrece una visión del general ante la gran cúpula donde permanece Akira criogenizado, dándonos ya una idea de lo peligrosa que llegó a ser la ciencia y apunta para nuestro interés unas pinceladas de lo que vendrá en páginas sucesivas. Lo que nos interesa es precisamente cómo Ôtomo trata el tema armamentístico desde un punto de vista moral y también legal. El plano no tiene desperdicio. Posee un efecto impactante de lo que se quiere transmitir, dando a entender lo que es Akira, qué tipo de arma es, y a qué nos enfrentamos. Hay también una utilización del lenguaje del manga magistral, sacando el máximo partido de la expresión gráfica (FIG.1).

Las leyes tratadas en las convenciones antes citadas prohíben aquellas armas que contengan elementos indetectables como el vidrio transparente, las balas dum-dum, o las bayonetas dentadas por causar un sufrimiento innecesario. De igual modo podemos decir que según para que se utilicen estas armas pueden ser lícitas o ilícitas, debiendo tener en cualquier caso un objetivo militar. Los cohetes V-2 que utilizaron los alemanes en la Segunda Guerra mundial eran ilícitos porque su imprecisión era tal que no sabían a ciencia cierta dónde estallarían. De la misma manera las bombas incendiarias utilizadas por los japoneses contra EE UU o, ya más cerca en el tiempo, la utilización de misiles Scud utilizados en la guerra de Irak, eran tan imprecisos que son considerados armas indiscriminadas. Como cabría pensar, las armas nucleares estarían dentro de este grupo ilícito por su destrucción masiva, sin embargo no es así ya que pueden ser muy precisas y destruir objetivos militares. Su uso ilícito es más bien moral pues hay una gran descompensación entre la destrucción del objetivo militar, la muerte de civiles y el daño medioambiental. Todos estos elementos afloran en el manga y en aquella frase se explicita que Akira tuvo que ser soterrado por estos motivos. El artículo 35 del Protocolo I de 1949 adicional a los Convenios de Ginebra proscribe aquellos medios de combate que "causen daños extensos, duraderos y graves al medio ambiente natural". ${ }^{4}$ A partir de la página 113 del segundo volumen, Kaneda utiliza un arma láser que disparará hasta que se le agote la batería contra, en ese momento su enemigo, Tetsuo. Bien, pues en el Protocolo IV de 1995 se prohíben las armas láser por que provocan ceguera (FIG. 2).

${ }^{3}$ Hoja informativa de la Cruz Roja. Resumen de los Convenios de Ginebra de 1949 y sus Protocolos Adicionales en http://es.scribd.com/doc/146969296/Convenios-de-Ginebra\#scribd. Cruzrojaamericana.org. Septiembre de 2006.

${ }^{4}$ Hoja informativa de la Cruz Roja. Op. cit.p. 5. 
AKIRA: arma de destrucción masiva

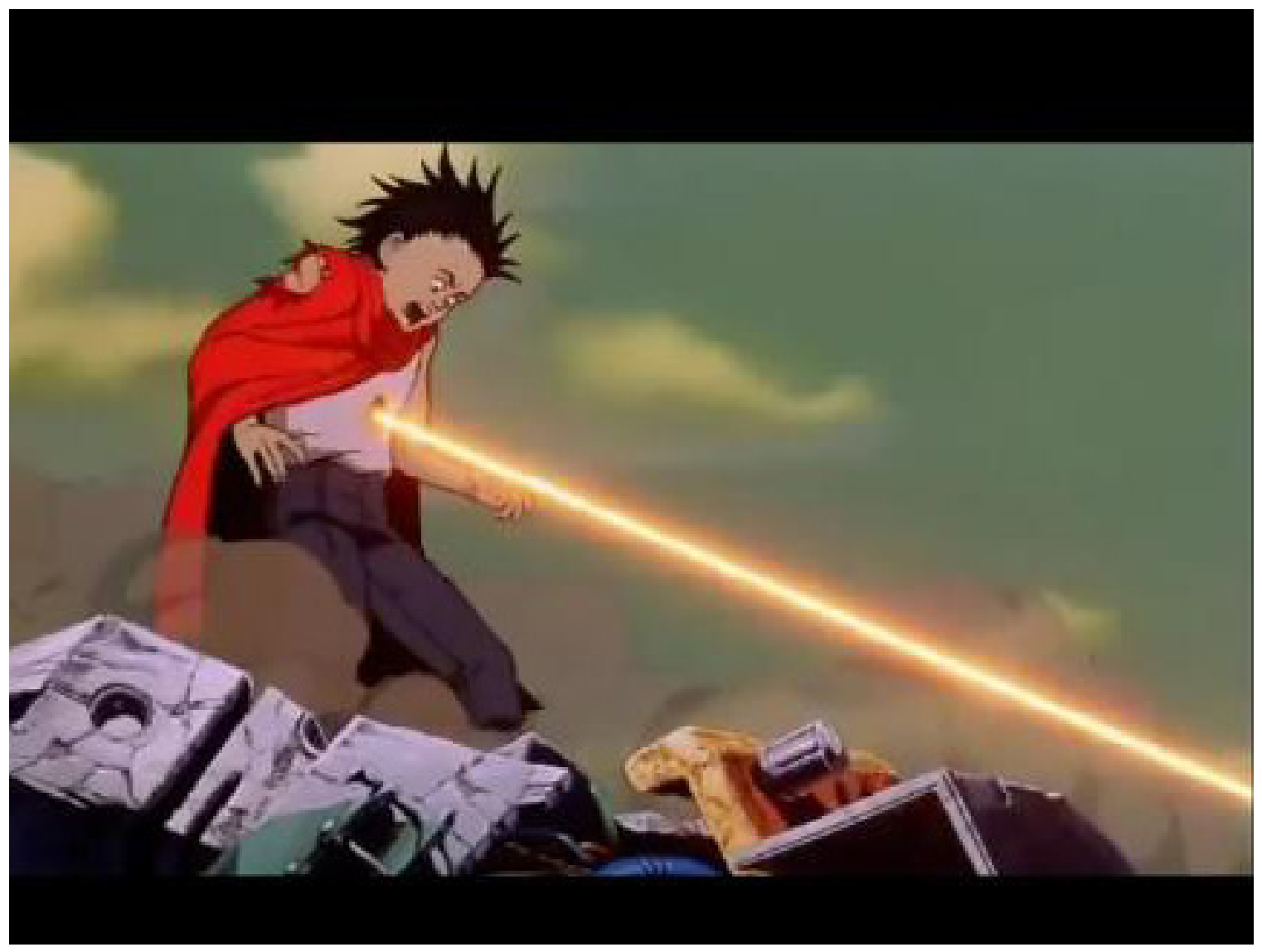

FIG. 2. Akira. Ôтомо, K. Fotograma. 1988, producción de Ryohei Suzuki y Shunzo Kato (Toho).

El Convenio sobre Armas Biológicas de 1972 prohíbe "la investigación, el desarrollo, la producción, el almacenamiento y la adquisición de armas biológicas y tóxicas". ${ }^{5}$ De estas armas ya se había debatido en anteriores congresos y probablemente se continúe hablando, pues aunque lo peligroso del asunto es su manipulación y conservación, países como Rusia mantenían un plan secreto admitido por Boris Yeltsin en 1992 de armas biológicas. ${ }^{6}$ En Akira no hay este tipo de armas pero sí en otra historia narrada por Ôtomo llamada Stink Bomb (FIG. 3), cortometraje introducido en la obra Memories, que trata sobre un accidente ocurrido por la confusión de un empleado de laboratorio al tomar una píldora equivocada y el personaje se convierte literalmente en una bomba fétida.

Según Terence Taylor, en 1991, Irak a pesar de firmar el Convenio Internacional de prohibición, poseía un programa avanzado de armas biológicas que incluía virus, bacterias y toxinas por lo que el gobierno americano lanzó la misión Tormenta del Desierto.

${ }^{5}$ Convención sobre la prohibición del desarrollo, la producción y el almacenamiento de armas bacteriológicas (biológicas) y tóxicas y sobre su destrucción. 1972 en http://www.cruzroja.es/dih/pdf/Convencion_de_1972_ sb_armas_biologicas_y_toxinicas.pdf

${ }^{6}$ Gutman, R. y Rieff, D. Op. cit. p. 70. 


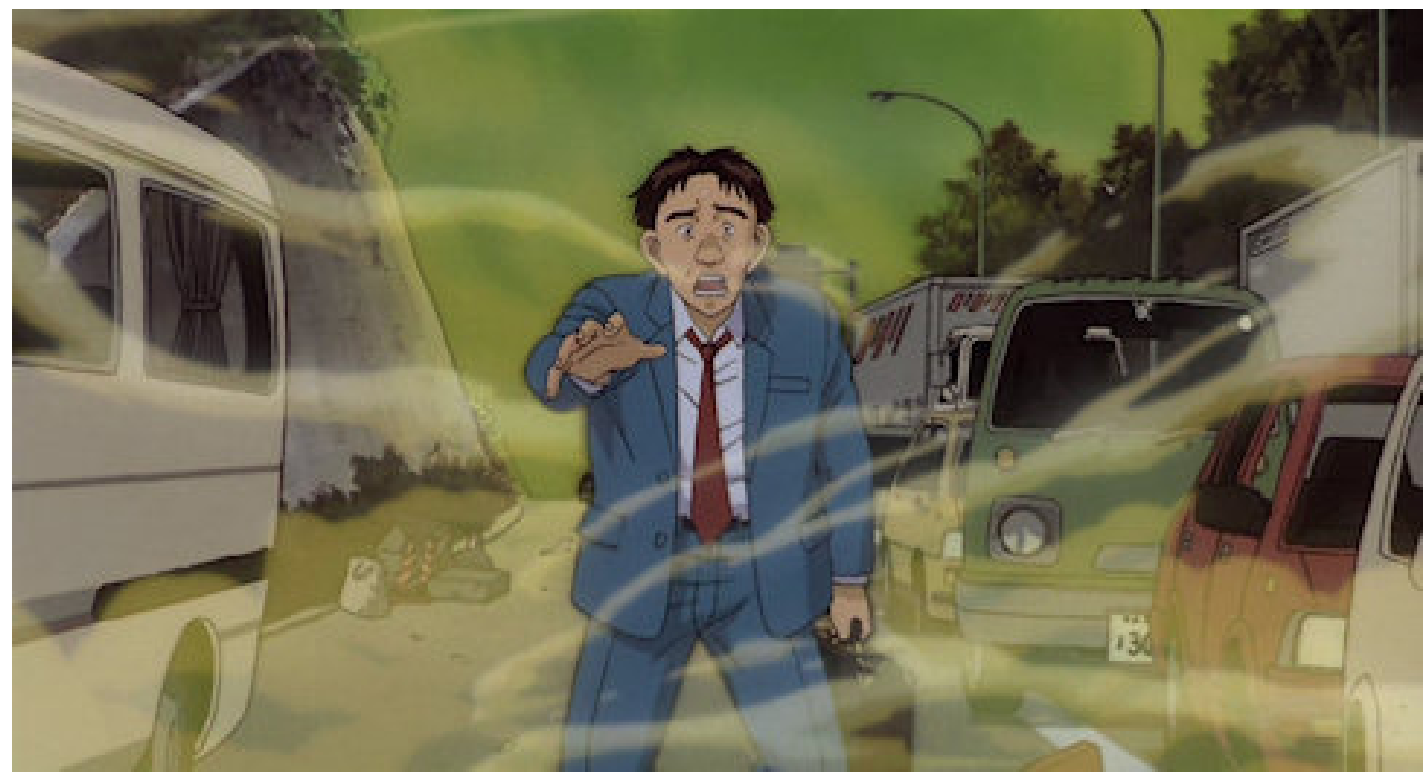

FIG. 3. "Stink bomb". Ôтомо, K. 1995. Corto de animación incluido en el anime Memories.

A partir de estos momentos tanto EE UU como Gran Bretaña adoptaron un programa preventivo contra el ántrax y otras toxinas neurotóxicas como el gas sarín (utilizado por la secta Aun Sinrikyo para perpetrar sus ataques en el metro de Tokyo) de la que debemos decir que es muy tóxica, pero mucho más lo es el ántrax, de la que, según estudios realizados, un misil que disemine 30 kilos de este producto puede matar entre 80.000 y 100.000 personas. Pero las hay peores. El ataque de mayores dimensiones hasta la fecha con armas tóxicas se produjo en la ciudad de Halabja el 15 de marzo de 1988, cuando tropas iraquíes gasearon a la población kurda durante tres días con gas sarín, tabún y el peor de todos: VX. Al menos 5.000 personas murieron en unas horas y con el tiempo los índices de enfermedades tumorales, cancerígenas y neuronales se han cuadruplicado en diez años, por no hablar de un número muy elevado de infecciones en la piel, los trastornos psicológicos severos, así como la traumática visión de la malformación corporal. En este caso parecía no haber dudas sobre el responsable, que fue Saddan Hussein, pues este personaje no ratificó los convenios protocolarios de 1977 vinculados al Tratado de Ginebra. Se sabe que Saddan Hussein utilizó gas en al menos sesenta ocasiones contra población civil por lo que se estiman en 60.000 las víctimas fallecidas bajo su mandato. En Akira se utilizan armas químicas varias veces. La primera vez que aparece utilizadas por un soldado americano es en la página 183 del tomo 5. ${ }^{\circ}$ (FIG. 4). Ryu intenta convencer al soldado para que nos las utilice: " ¡no puedes usarlas aquí! ¡Matarías a todos! ¡Piensa en la gente! ¡no sólo los súbditos del imperio, sino también los refugiados y los voluntarios de la Cruz Roja!”. Más adelante, en la página 71 del tomo $6 .^{\circ}$, este mismo soldado comenta apuntando a Tetsuo: "desarrollar los gérmenes de este gas les llevó mucho tiempo a los ingenieros de genética...” y a continuación se produce un disparo que produce justo el efecto contrario porque Tetsuo estaba convertido en un monstruo y de repente cobra apariencia de normalidad absoluta y un bienestar antes ignorado. Como respuesta Tetsuo le hace explotar su cabeza. 


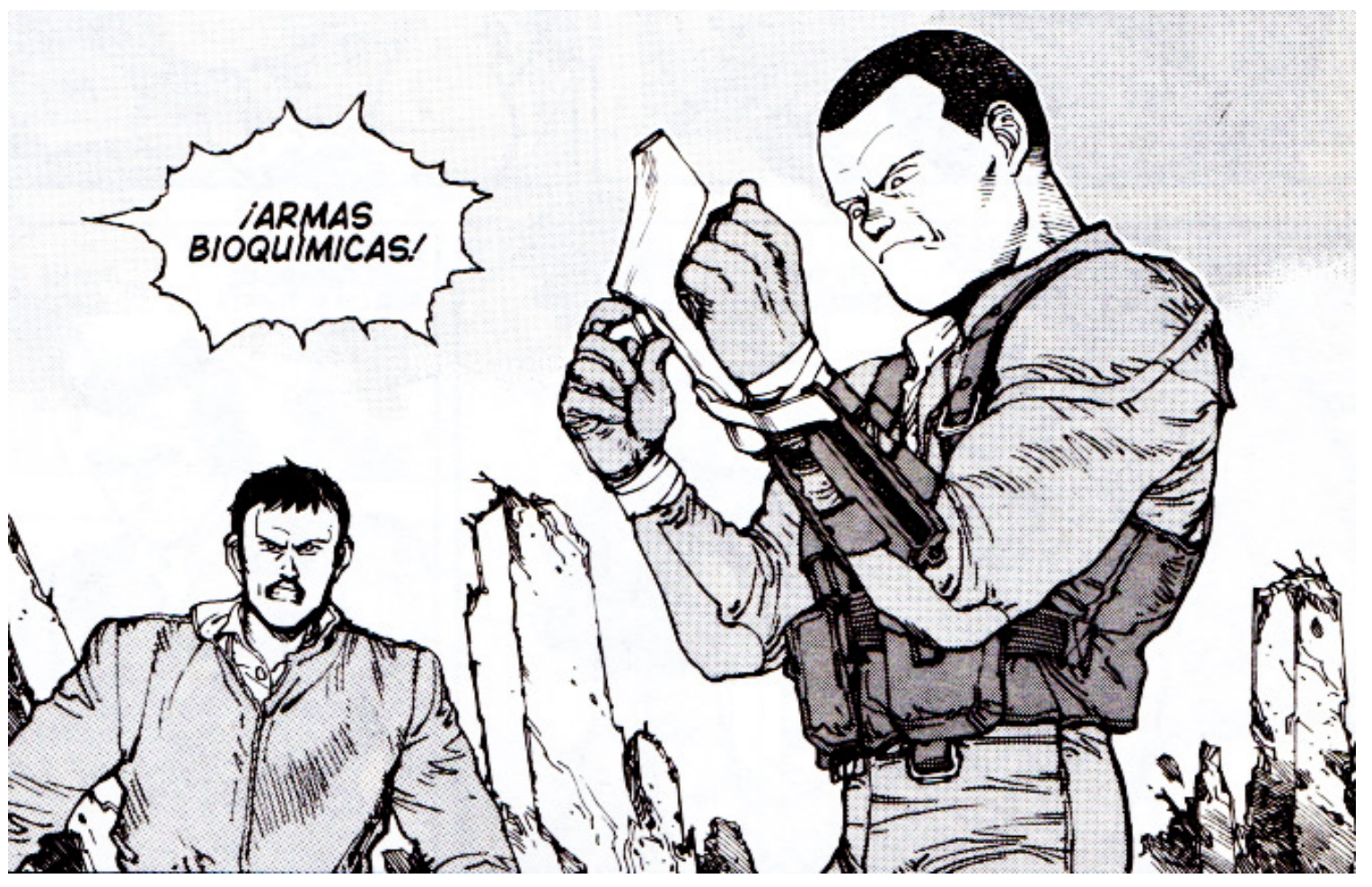

FIG. 4. Ôтомо, K. Op cit.Vol. 5. , p. 183.

Pero ha habido otros casos relevantes de acciones militares con armas químicas. El primero de ellos se produjo durante la Primer Guerra Mundial (1914-1919), en la segunda batalla de Yprés, el 22 de abril de 1915, Alemania usó contra las tropas enemigas 180 toneladas de clorhídrico asfixiante, causado la intoxicación de 15.000 de personas, de las que fallecieron 5.000. Durante la guerra sino-japonesa (1937-1945), en la batalla de Wuhan, el ejército japonés usó armas químicas a través de la Unidad 516, entre ellas gas mostaza, lewisita, fosgeno y cianuro. Las víctimas mortales de militares y civiles chinos se estiman en 80.000 relacionadas solo con armas químicas. El caso más impactante por su atrocidad quizás sea los continuos ataques con Agente Naranja que arrojaron los aviones estadounidenses hacia la selva vietnamita (1957-1975), eliminando y malformando la vida de todo aquello que tocaba. En un principio el objetivo era eliminar la densa foresta que impedía la visión de los objetivos militares, pero el Agente Naranja fue penetrando en poblaciones enteras contaminándolo todo. El Agente Naranja es un potente herbicida (Dioxina) que modifica eficazmente la genética de los descendientes de los afectados, dando lugar a malformaciones indescriptibles incluso tres generaciones después de su vertido.

Con respecto a las armas nucleares, que es quizás la comparación más acertada entre lo que es el personaje de Akira y un arma real, en 1994 el Tribunal Internacional de la Haya concluyó:

[la] amenaza del uso de armas nucleares podría ser contraria a las normas del derecho internacional aplicables a un conflicto armado, y en particular a los principios y a las normas del derecho humanitario. 
Sin embargo, en vista del estado actual del derecho internacional y de los elementos factuales a su disposición, el Tribunal no puede concluir de forma definitiva si la amenaza o el uso de armas nucleares seria legal o ilegal en circunstancias extremas de autodefensa en la cual la supervivencia misma de un estado estaría en peligro. ${ }^{7}$

En la actualidad hay cinco países que poseen y pueden poseer armamento nuclear: EEUU, Rusia, Gran Bretaña, Francia y China. Han manifestado el deseo de su posesión India y Pakistán. ${ }^{8}$ Akira por su parte permanece bajo tierra como un arma nuclear muy destructiva, de hecho la bomba que inicia el manga no es tal, sino que a lo largo de las páginas, en torno al volumen cuarto, se revela que la provocación de la III Guerra Mundial fue Akira y ese es el motivo por el que lo criogenizaron y mantuvieron en esas condiciones bajo tierra.

Quizás la clave de Akira como obra maestra resida en el hecho de mezclar el desastre, la guerra y los niños. Todo ello lleno de contrariedad, empezando porque la temática de la historia de Akira es la amistad, pero no se explicita nada de ello, es a través de su lectura que este sentimiento afectuoso cobra fuerza. En 1994 Kenzaburo Oé recibió el premio Nobel de literatura y en su discurso titulado Japón, la ambigüedad y yo expresaba justo esa idea de que se ha incumplido el ideal antinuclear basado en "no fabricar, no poseer y no utilizar armas atómicas". ${ }^{9}$ Pero al mismo tiempo han continuado el rearme y la militarización sobre todo en Okinawa, donde continúan las bases militares estadounidenses.

\section{Experimentos}

Lo más espeluznante de la comparación histórica que estamos haciendo entre el manga de Akira y los distintos tipos de armas de guerra es, que el personaje que encarna Akira no es otra cosa que un experimento biológico con un niño que había manifestado una serie de poderes (FIG. 5). Existían una red de campos de experimentación a partir de la anexión de los territorios manchures entorno al año 1937 que se extendía desde Mongolia hasta Singapur y desde Bankog hasta Manila, territorio conquistado por Japón hasta la fecha, cuyo teniente a cargo era Shiiro Ishii, un médico militar que consiguió situarse al frente del mando militar y así poder llevar a cabo programas de experimentos biológicos con humanos. Cada campo contaba con un número de cirujanos, farmacólogos, botánicos, biólogos y médicos militares al servicio de las pruebas que ordenaba Ishii. Se calcula que murieron entre 12.000 y 15.000 personas, hombres, mujeres y niños.

Las actuaciones llevadas a cabo fueron sobre todo infectar a los reclusos con todo tipo de tóxicos biológicos y enfermedades virales para observar su proceso, inyectar distintas soluciones para ver su reacción y documentar los resultados. El objetivo fue siempre el mismo, dominar Asia y expandirse para conquistar más territorios y para ello pensaron que eran

\footnotetext{
7 Pigrau Solé, A. El empleo de armas nucleares ante el derecho internacional humanitario, p. 152 en http://www. frdelpino.es/wp-content/uploads/2014/10/en_6-Antoni-PIGRAU-SOL\%C3\%89.pdf.

${ }^{8}$ En julio de 2015 parece que ha habido un acercamiento amistoso entre EEUU e Irán, comprometiéndose este último a no crear armas nucleares, acontecimiento notablemente celebrado por las autoridades occidentales.

${ }^{9}$ Kenzaburo, O. Cuadernos de Hiroshima. Barcelona, Anagrama, 2011.
} 
AKIRA: arma de destrucción masiva

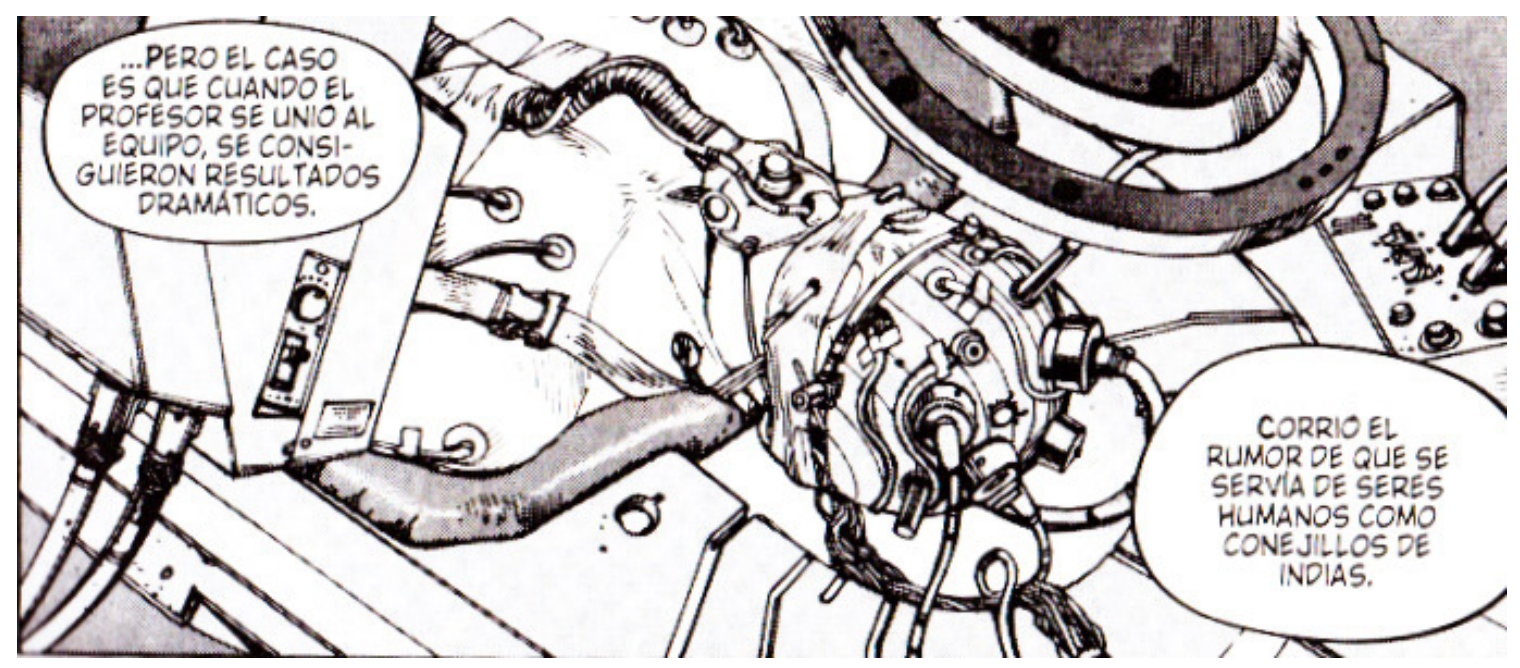

FIG. 5. Ôтомо, K. Op cit. Vol. 4. ${ }^{\text {, p. }} 183$.

imprescindibles estos experimentos, así como armas biológicas, y antes de lanzarlas en el campo de batalla, serían probadas en humanos. El centro de estas operaciones era Ping Fan entre otros, un área retirada perteneciente a la ciudad de Harbin, al norte de China. Inyectaban toxinas directamente sobre los campesinos haciéndoles creer que eran vacunas. ${ }^{10}$ Pero esto era lo más suave, pues como se conoce a esas personas le practicaron a continuación la vivisección ya que el objetivo era observarlo in situ. Imágenes similares vemos en Akira, donde el autor ofrece distintos momentos de la experimentación con los niños. El derecho internacional prohíbe el uso de métodos bacteriológicos desde 1925 según el Protocolo de Ginebra como respuesta a las armas empleadas en la Primera Guerra Mundial, sobre todo el gas mostaza, y en 1945 en el proceso de Nuremberg se declaró estos experimentos científicos no como crímenes de guerra sino como crímenes humanos. Estos acuerdos fueron ratificados en el Convenio de Ginebra de 1977 que prohibió su uso, incluso con el consentimiento del sujeto. En Harbin También se cometieron experimentos de resistencia física, al igual que los cometieron los médicos militares alemanes. En la historia de Akira se pueden ver algunas páginas conmovedoras en este sentido en el tomo sexto en torno a la página 357. En viñetas anteriores hay una explicación de una voz que intenta justificar estos experimentos cuando dice " ¿acaso dudas de la capacidad del espíritu humano para elegir su camino?” A lo que Kaneda responde: “¡Gilipollas! ¡Nadie me va a hacer creer que Tetsuo y todos los pequeños mutantes arrugados del laboratorio representan las aspiraciones de la raza humana!" Y a continuación aparecen las viñetas con aquellos niños en "guarderías" rodeados de científicos y los niños conectados a grandes máquinas y con el cráneo tapado con una protección metálica donde podemos leer: "la mayoría no conoció más suerte que la

${ }_{10}$ Para más información véase el artículo "Japanese biomedical experimentation during the World-War-II era" de Sheldon Harris o páginas relacionadas con la "Unidad 731". Parece increíble como las normas del Convenio de Ginebra de 1925 sobre la prohibición de armas biológicas que fueron repartidas en folletos para no fomentar la investigación de armas biológicas, llegaron a manos del médico Ishii, para este, acto seguido, hacer todo lo contrario de aquellas recomendaciones y comenzar a pensar en un programa de armas de destrucción masiva. La documentación y los testimonios son espeluznantes. También se hizo una película, Man behind the sun (Tun Fei Mou, 1988) que narra estos hechos. 
muerte o la locura, y muchos que vieron la fuerza desarrollarse en ellos fueron abandonados, totalmente enfermos, la fuerza sólo les ha traído miseria...”. (FIG. 6)
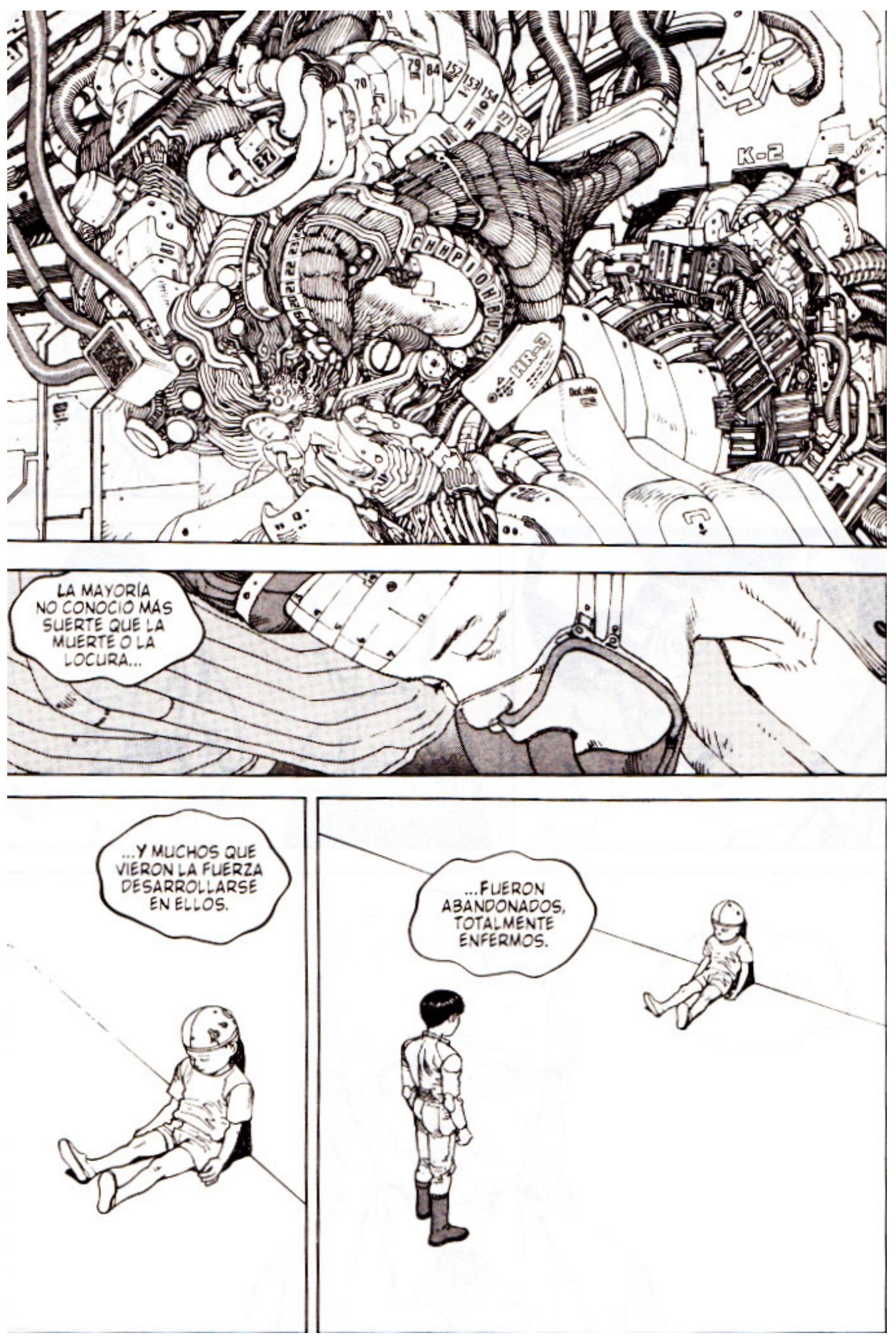

FIG. 6. Оิтомо, K. Op cit. Vol. 6. ${ }^{\circ}$, p. 359. 
En el caso de Japón los crímenes fueron juzgados parcialmente, de hecho muchos de los médicos que cometieron atrocidades fueron incorporados a la vida cotidiana de posguerra. Además debido a que después de la guerra Japón fue ocupado por los EE UU, a estos le interesaba toda la información de aquellos experimentos, por lo que han sido silenciados al máximo posible. Se ha estimado en 10.000 los folios que los norteamericanos se llevaron con toda la información. ${ }^{11}$ Aunque las crueldades mayores fueron llevadas a cabo por los nazis. Son múltiples los ejemplos llevados a cabo por el Doctor Mengele, llamado «el ángel de la muerte». Debido a que el nazismo tenía como objetivo una raza superior de arios comenzaron a realizar una serie de experimentos con los prisioneros que aportara mayor conocimiento y más específico entorno al comportamiento del cuerpo en general así como su resistencia en condiciones adversas. Se han descrito numerosas torturas de las que tomaremos una muestra: introducir a un individuo en agua helada para saber a qué temperatura muere un hombre por congelación. A otros hombres antes de que perecieran se les sacaba de este baño helado para introducirlos en otro baño, en este caso de agua hirviendo. Amputar las extremidades y coserlas en otros individuos con el objetivo de observar si el cuerpo era capaz de actuar con los miembros de otros, etc. Al parecer al doctor Menguele le gustaban especialmente los gemelos y los niños. Con los primeros intentaba ver si causándole daño a uno, el otro reaccionaba. Y con los segundos constan casos de haber cosido niños por la espalda a pares con la intención de que se convirtieran en siameses, pensando que sus cuerpos se unirían de forma natural. ${ }^{12}$

El experimento particular del manga de Akira está descrito por Lady Miyako en una conversación que mantiene con Tetsuo, ya que este ha ido a hacerle una visita por su confusión mental (página 182 del volumen $4 .^{\circ}$ ):

Todo empezó en los años sesenta... con un proyecto sin importancia, ni siquiera cifrado... Estaba a cargo de un puñado de gente del ministerio de defensa, cotejando datos y analizándolos... En los setenta, a raíz de sus descubrimientos, se reunió a un grupo de gente que presentaba una serie de rasgos singulares. Los científicos experimentaron con ellos, haciéndoles realizar una suerte de entrenamiento... Fue entonces que cierto profesor, sumamente polémico, empezó a mostrarse interesado. $\mathrm{Su}$ especialidad era el funcionamiento fisiológico del sistema nervioso central. En aquel entonces la fisiología nerviosa no estaba todavía estructurada y la mayoría de los colegas del profesor desaprobaron sus experimentos... pero el caso es que cuando el profesor se unió al equipo, se consiguieron resultados dramáticos. Corrió el rumor de que se servía de seres humanos como conejillos de indias. [...] Construyeron tubos de vidrio minúsculos, más pequeños que los vasos sanguíneos... y llenaron esos tubos con agua salada. Insertaban esos tubos en las células nerviosas de los cerebros de los pacientes estimulándolas repetidamente con descargas eléctricas siguiendo pautas específicas con miras a alterar la composición genética. A continuación inyectaban directamente en el material genético de los pacientes la solución que habían obtenido de aquella manera. A esos niños los designaban con códigos... En una veintena. A todos los niños involucrados en el proyecto y que adquirieron poderes, les asignaron códigos numéricos. Pero los números veinte no eran corrientes, se reservaban para aquellos que mostraban dones superiores [...] Y el niño al que llamaban... número 28... destruyó Tokio... y acabó con el profesor que le había creado y el historial del proyecto. Los únicos supervivientes fueron el mismo Akira... y otros tres niños que ya conoces. Tardaron tres años en averiguar que la catástrofe tenía que ver con aquel proyecto, y el gobierno tardó mucho en permitir la reapertura del proyecto. (FIG. 7).

11 Veracity, D. Experimentos médicos en seres humanos... en los EEUU. 2006. Del sitio web Naturalnews. Traducción de Adela Kauffman en http://www.bibliotecapleyades.net/ciencia/ciencia_industryweapons178.htm. 12 Herradon Ameal, O. La Orden Negra. El ejército pagano del III Reich. Barcelona. Edaf. 2011. 


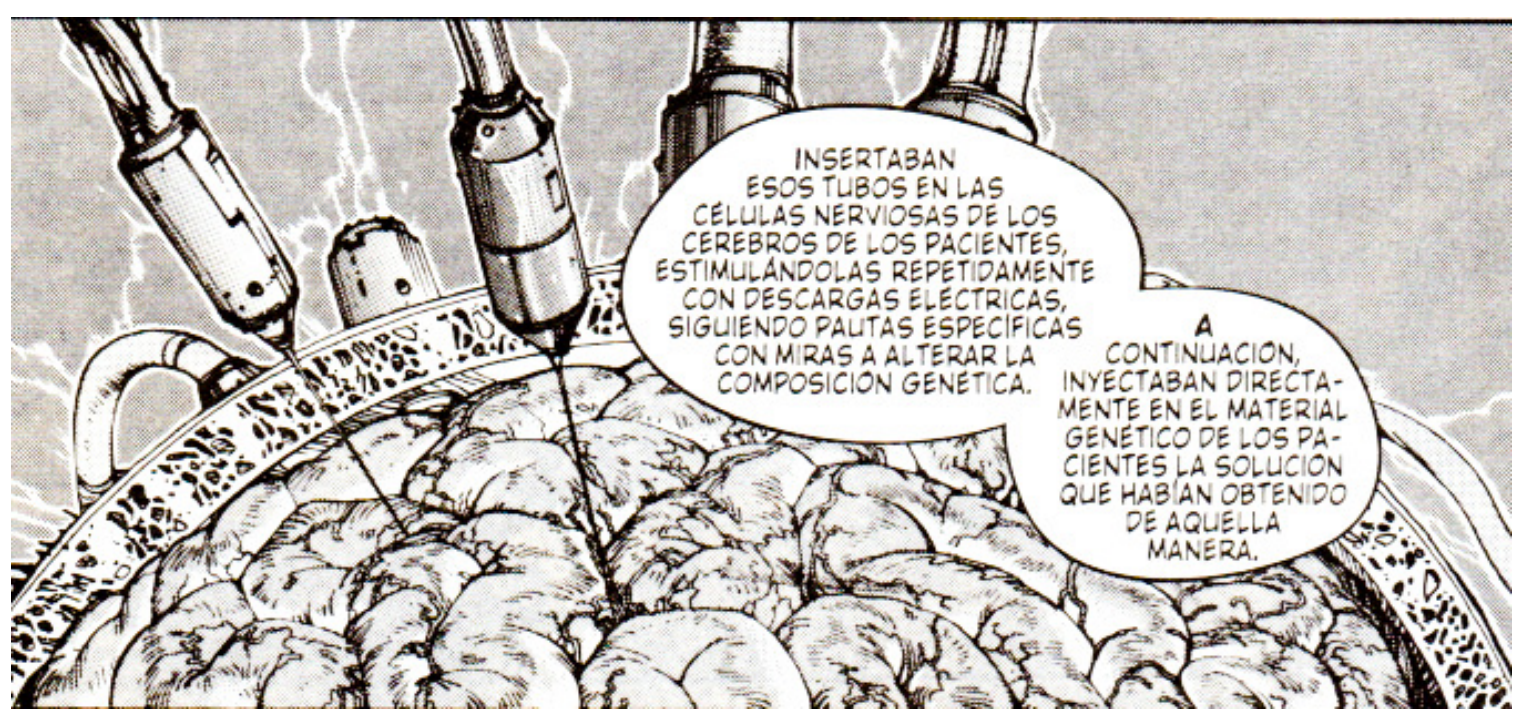

FIG. 7. Оิтомо, K. Op cit.Vol. 4. ${ }^{\circ}$, p. 184.

En el Estatuto de Roma de la Corte Penal Internacional se define nuevamente todas las normas de la guerra, que habían sido expuestas en el Convenio de Ginebra. Concretamente en el Articulo 8..$^{\circ}$, punto 2, apartado a), sección II, declara como crimen de guerra: "La tortura o los tratos inhumanos, incluidos los experimentos biológicos". En el apartado b), sección $\mathrm{X}$ de ese mismo artículo se manifiesta la prohibición de:

Someter a personas que estén en poder de una parte adversa a mutilaciones físicas o a experimentos médicos o científicos de cualquier tipo que no estén justificados en razón de un tratamiento médico, dental u hospitalario, ni se lleven a cabo en su interés, y que causen la muerte o pongan gravemente en peligro su salud. ${ }^{13}$

Y así un rosario de normas que están puestas precisamente porque en algún momento se cometieron estas barbaridades.

En 1975 se firmó un acuerdo que ratificaba la prohibición de armas biológicas. Fue firmado por los principales dirigentes URSS, Gran Bretaña y EE UU. A partir de este momento este acuerdo fue ratificado por 140 países. El problema radica en el compromiso verídico de los mismos a cumplir el acuerdo ya que en la actualidad sólo la mitad de estos países hacen una entrega voluntaria correspondiente a los informes requeridos ${ }^{14}$. Hemos de añadir que los EE UU desde el gobierno Bush (2001) no ratifica el acuerdo según afirmó el representante de EE UU Donald Mahley "A nuestro entender, el borrador del protocolo podría poner en riesgo la seguridad nacional y la información confidencial". ${ }^{15}$ En 2006 el gobierno de

13 VVAA. Estatuto de Roma de la Corte Penal Internacional. Brussels, 17 July 2014, p. 7 en www.iee.es/.../ Internacional/2014/CortePenalInternacional_EstatutodeRom...

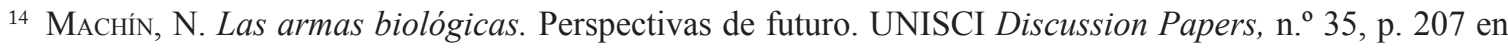
revistas.ucm.es/index.php/UNIS/article/viewFile/46428/4362

15 Gutman, R. y Rieff, D. Op. cit. p. 69-71. 
Clinton tampoco firmó el acuerdo y el actual presidente Barak Obama tampoco, alegando las mismas disposiciones.

En España existe un grupo llamado GRUPABI (Grupo de Armamento Biológico) que está vinculado al OPAQ(Organización para la Prohibición de Armas Químicas), organismo creado con el objetivo de eliminar las armas químicas a nivel mundial. También existe en la actualidad un giro con respecto a cómo se ha entendido la experimentación científica apareciendo peligrosas nuevas líneas de investigación en el campo de la ingeniería genética o genómica, lo que apunta la experimentación biológica desde el punto de vista del cruce, la mutación y la creación de genomas que pueden ser utilizados como armas bélicas. Por estos motivos en 2006 la INTERPOL redactó un programa de prevención contra el bioterrorismo.

\section{E1 Proyecto Manhattan}

El Manhattan Engineer District, nombre oficial de lo que hoy conocemos como Proyecto Manhattan, fue una iniciativa norteamericana para crear bombas nucleares ante el temor de que antes lo hicieran los alemanes nazis. A la cabeza del proyecto se nombró a Lieslie Groves y al carismático Robert Oppenheimer que unió a un equipo de científicos que, sin dar toda la información, fueron reunidos bajo el mandato del presidente Roosevelt en Los Alamos, un paraje desierto que había elegido como lugar encubierto de sus experimentos nucleares. Para la creación de la bomba contaron con 37 fábricas y laboratorios de 19 Estados y de Canadá. Se emplearon 120.000 personas y los mejores científicos del país. Esto sucedió entre 1941 y $1945 .{ }^{16}$

Más tarde, en 1944, los EE UU se enteraron de que Alemania había abandonado el proyecto de crear una bomba atómica, pero ya era demasiado tarde, porque aunque se ha discutido mucho acerca de los motivos del lanzamiento de la bomba, a estas alturas, después de haber invertido tanto dinero (dos mil millones de dólares de la época) y esfuerzos en llevar a cabo el proyecto, los EE UU, con Truman ahora como presidente, no sólo querían finalizar la guerra sino mostrar su superioridad armamentística también a los rusos que observaban expectantes. Además las incursiones a pie en otras batallas militares, por ejemplo en Okinawa se habían cobrado muchas vidas de soldados americanos y con la utilización de la bomba se ahorraría tanto en vidas como en sueldos. Y finalmente, por qué no decirlo, todo el equipo se sentía excitado porque efectivamente había nacido una nueva forma de trabajar entre las fábricas y los científicos y ya las pruebas resultaron demoledoras, en el sentido de que esos años de esfuerzo y trabajo en el laboratorio por fin daban sus frutos y de alguna manera ellos mismos se habían sugestionado para pensar que hacían un bien patriótico y humano, por lo que no había ningún motivo para no lanzarla. Se sentían, en última instancia, pode-

16 López aguilera, E., Prado Rodríguez, D. y Sastre Miguel, A. Manhattan project: «el papel de los científicos en el desarrollo de la bomba atómica». 1999 en http://upcommons.upc.edu/bitstream/handle/2099/9730/ Article019.pdf;jsessionid=D18089D82500FF1A80E53DA6B5BF1FF7? sequence=1ESILldianres de la ETSETB. Para profundizar en el tema véase Preston, D. Antes de Hiroshima, de Marie Curie a la bomba atómica. Barcelona, Tusquets, 2008. 
rosos y deseosos de poder, y su ejecución lo confirmaría. ${ }^{17}$ En Akira encontramos numerosos estallidos de energía que provocan el mismo efecto que la bomba. Además, vemos que la cámara donde dormita cuando es desenterrada por Tetsuo es de las mismas formas que los proyectos donde se almacenaron las primeras bombas atómicas (FIGS. 8 y 9).

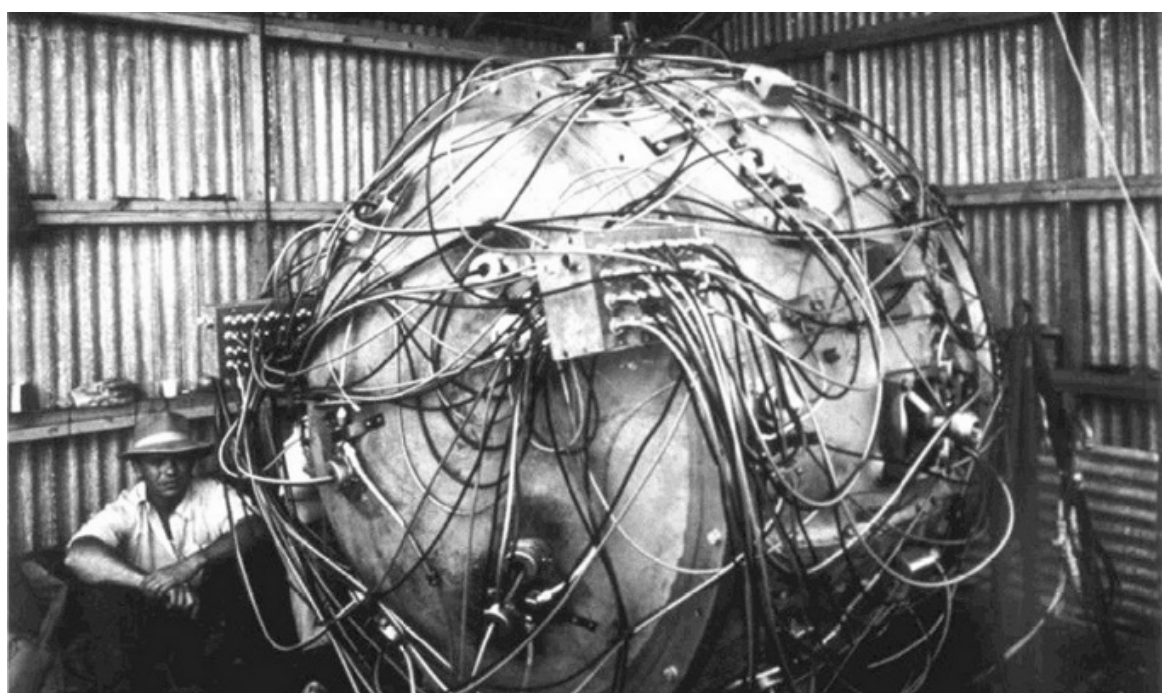

FIG. 8. Bomba de fisión compuesta de plutonio 239-Trinity/Gadget. Foto: Osti.gov

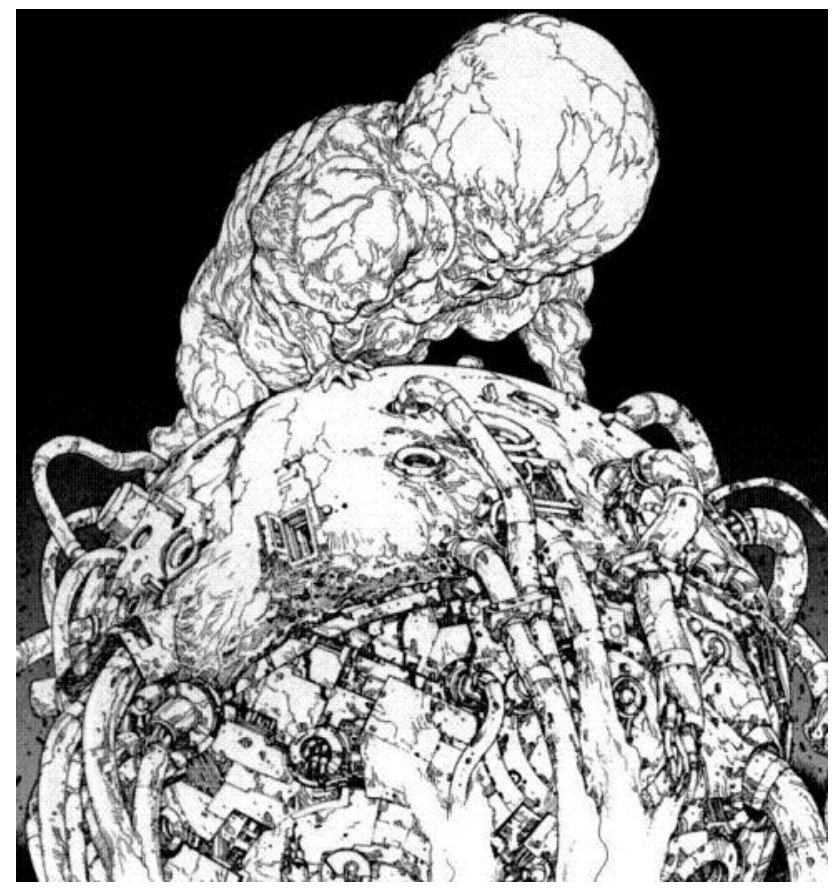

FIG. 9. Ôтомо, K. Op cit. Vol. 6. ${ }^{\circ}$, p. 260.

17 Hobsbawn, E. Historia del siglo XX. Buenos Aires, Crítica, 1998, p. 35. 
El Secretario de Guerra Stimpson creó un comité que se reunió tres veces para resolver las pesquisas del lanzamiento: en qué ciudad, sobre qué punto, a qué hora, etc. Fue el 6 de agosto de madrugada que partieron tres aviones de grandes dimensiones (B-29) y el que portaba la bomba, al que llamaron Enola Gay. La bomba fue lanzada para que cayera sobre el puente Aioi, un puente en forma de T situado en el centro de Hiroshima. Hizo explosión a 700 metros de altura y se cree que mató a unas 100.000 personas. Los testimonios vivos lo cuenta con un infierno absoluto: cuerpos carbonizados y cortados por todas partes. La arquitectura quedó arrasada, tan solo se mantuvo en pie un edificio que era el único de la ciudad construido en hormigón y que han mantenido en memoria de aquel día, el resto eran casas tradicionales de papel y madera. En los días sucesivos se hicieron grandes piras para deshacerse de los cuerpos y controlar las epidemias, el olor a carne quemada, cuentan, era insoportable.

Al parecer algunos científicos se retractaron después de ver los efectos devastadores en Japón y crearon el llamado "Movimiento Científico" que intentaban persuadir al gobierno para retrasar el uso de energía atómica en actos militares; concretamente fueron científicos tan reputados como Niels Bohr o James Frank. ${ }^{18}$ Este comienzo fue creciendo y el grupo científico se unió en noviembre de 1945 bajo las siglas FAS (Federation of Atomic (American) Scientistis). Esto les llevó a crear al año siguiente otro organismo dispuesto a tener el control de la energía atómica (AEC) Atomic Energy Commision. A partir de estos momentos ha habido un control sobre todo lo relativo a los asuntos que tengan que ver con lo atómico y nuclear a nivel mundial, pero no será hasta mucho más tarde que el presidente Kenedy prohibiera las pruebas y ensayos con bombas atómicas de las que han quedado numerosas grabaciones (FIGS. 10 y 11 ).

Se cuenta que a las pocas horas de caer la bomba comenzó a caer una lluvia color negro que comenzaron a beber porque no tenían agua en ningún otro sitio y había mucha gente con quemaduras severas, esta agua de lluvia resultó de lo más perjudicial pues había arrastrado toda la radiación del cielo. Shoei Imamura lo narra en su película Kuroi ame (Lluvia negra, 1989).

Cada superviviente de Hiroshima y Nagasaki tiene su historia. Llama la atención el caso de muchos ancianos que han quedado sin familia e intentan suicidarse porque no quieren formar parte de la lista de víctimas de guerra porque para ellos es una humillación. Los médicos cuentan cómo venían pacientes sin síntomas físicos evidentes y que sin embargo morían a las pocas semanas, a causa de hemorragias internas causadas por la radiación.

Además en estos momentos se desconocía los efectos de la radiación, en el ensayo llevado a cabo en el atolón Bikini, en las islas Marshall, situadas en el Pacífico Sur, el 1 de marzo de 1954 la radioactividad afectó a los 239 habitantes de la periferia. 49 murieron en los doce años siguientes. De igual modo terminaron los 28 observadores meteorológicos norteamericanos y 32 tripulantes del pesquero japonés Dragón de la suerte $V$, que faenaba en la zona. $^{19}$

18 López aguilera, E., Prado Rodríguez, D. y Sastre Miguel, A. Op. cit. p. 63.

19 Kenzaburo, O. Cuadernos de Hiroshima. Barcelona, Anagrama, 2011. 


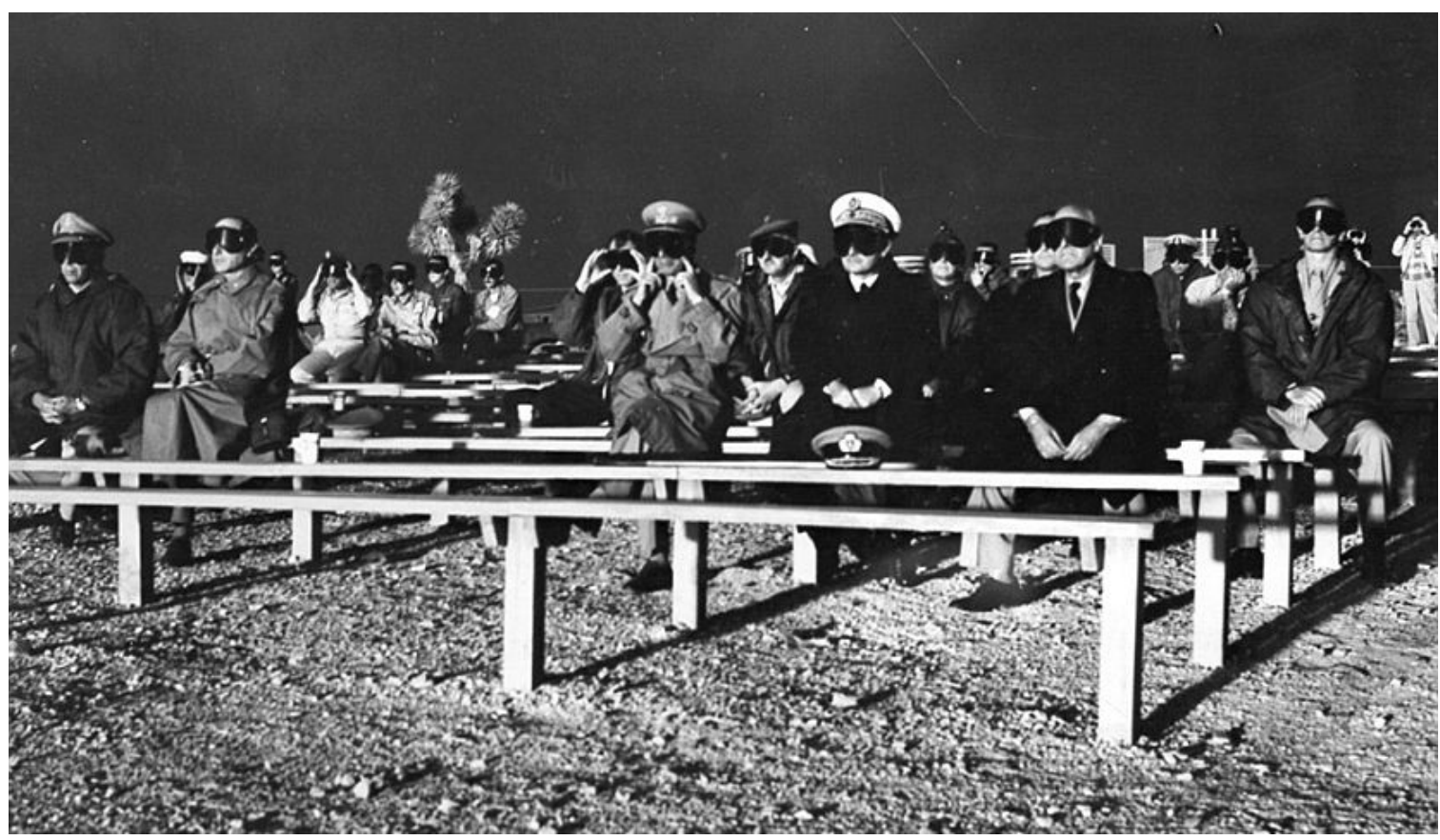

FIG. 10. Observadores de la OTAN miran la explosión de la Operación Plumbbob Boltzmann el 28 de mayo de de 1957 Foto: National Nuclear Security Administration / Nevada Site.

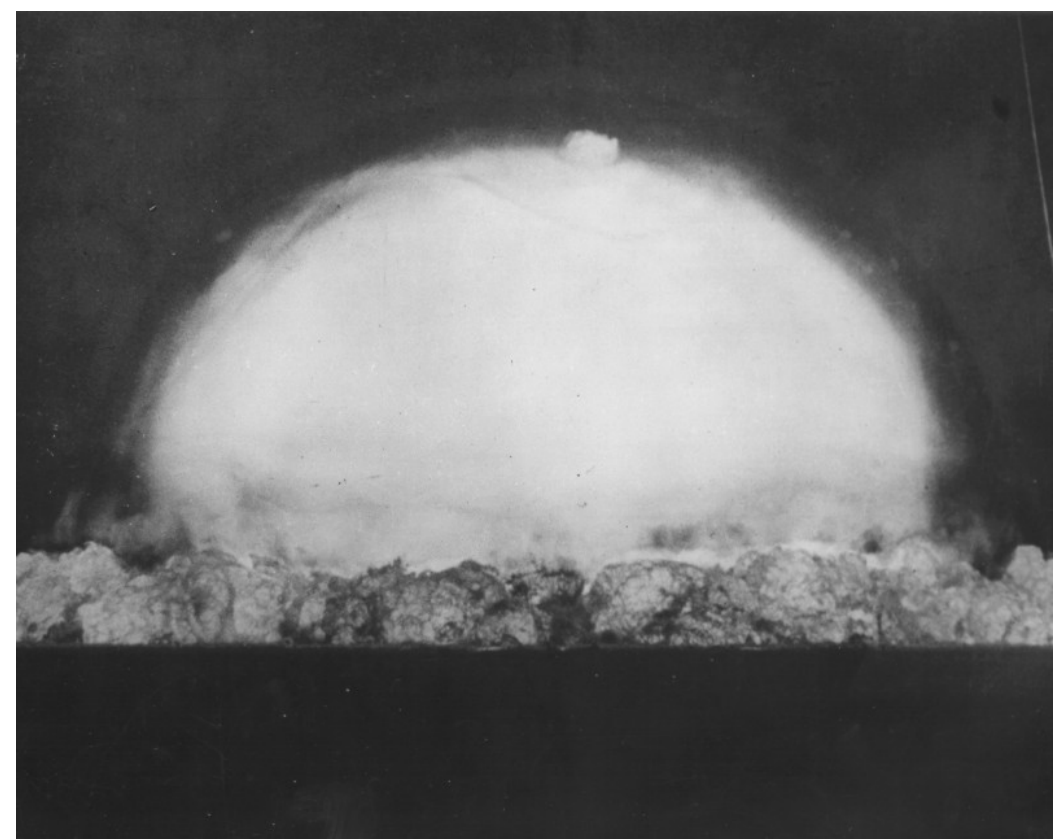

FIG. 11, prueba atómica TRINIDAD. Alamogordo, Nuevo México, 16 de julio 1945, 15 segundos después de su detonación, se eleva en el aire sobre el desierto cerca de la ciudad de San Antonio. Foto: National Nuclear Security Administration / Nevada Site. 
AKIRA: arma de destrucción masiva

El manga Akira recoge numerosas explosiones de energía que tiene los mismos efectos que la bomba atómica y que apuntan directamente a ella (FIGS. 12, 13 y 14).

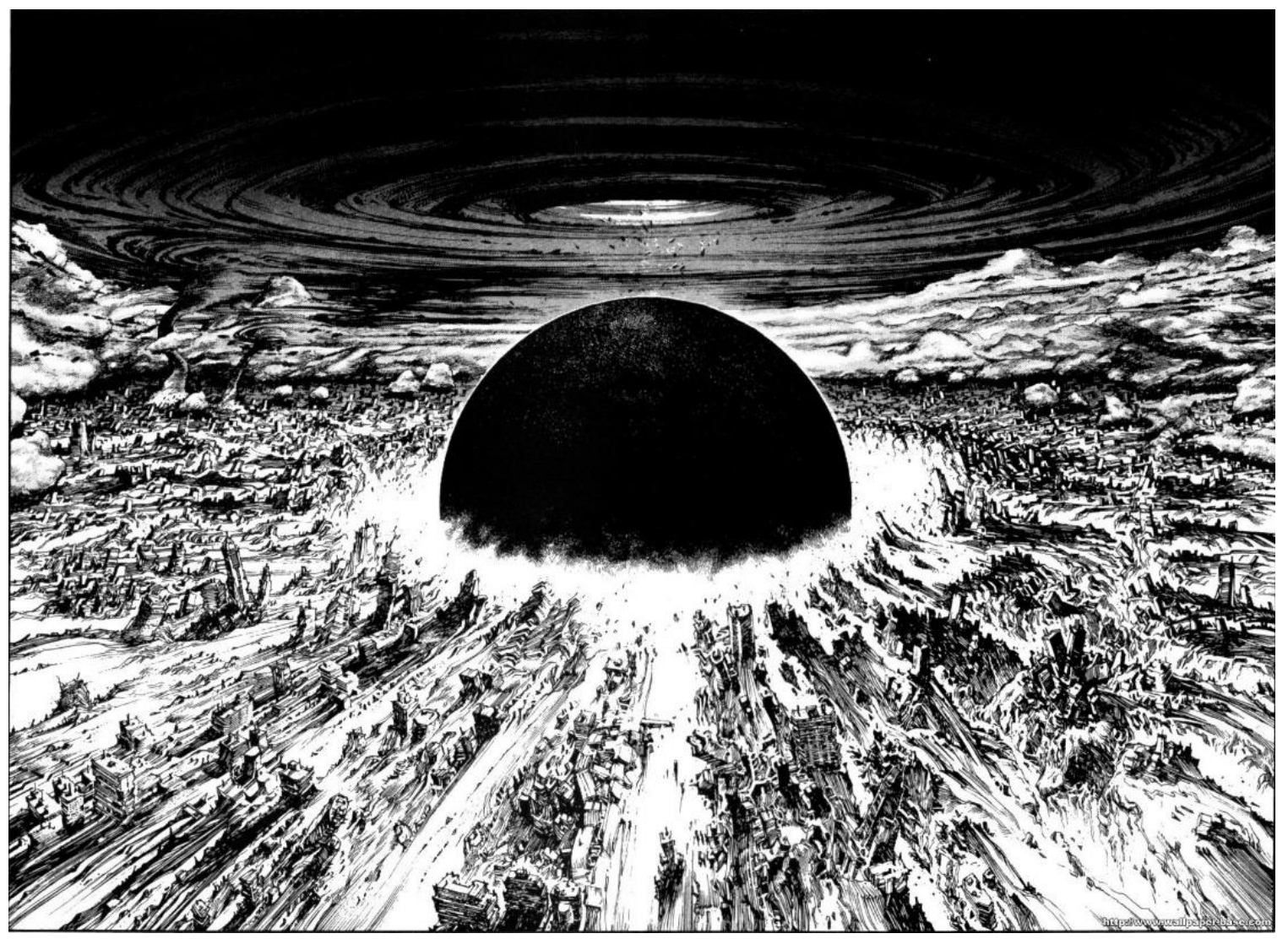

FIG. 12. Оิтомо, K. Opcit. Vol.3.o,pp.266-267.

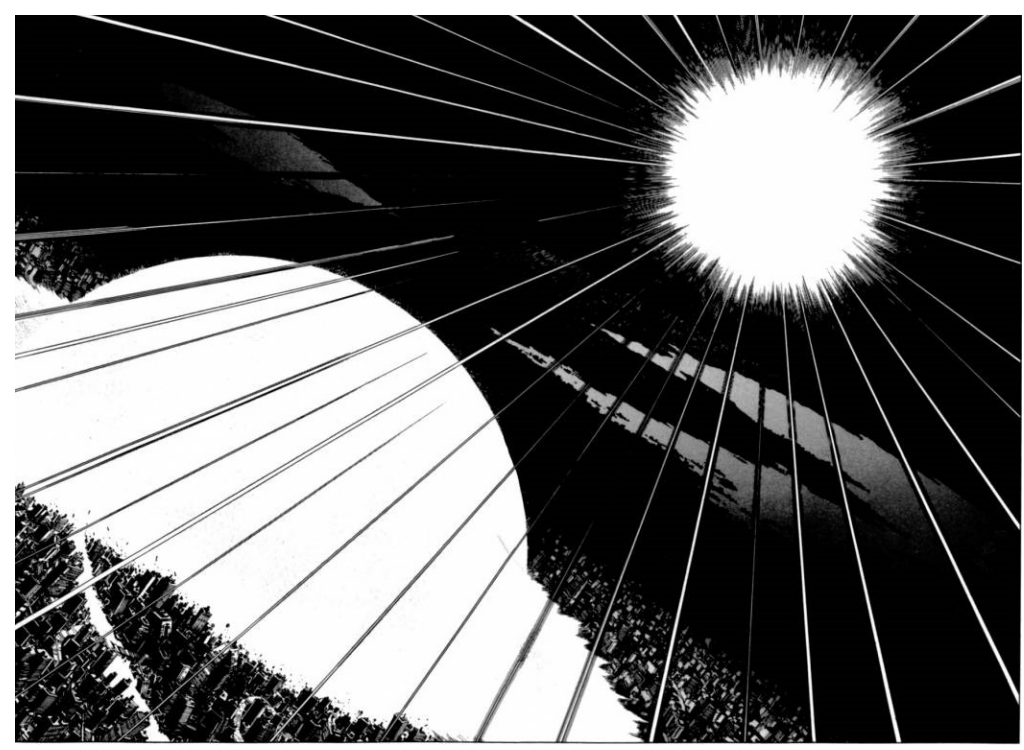

FIG. 13. Оิтомо, K. Opcit. Vol.6. ${ }^{\circ}$,pp. 330-331. 


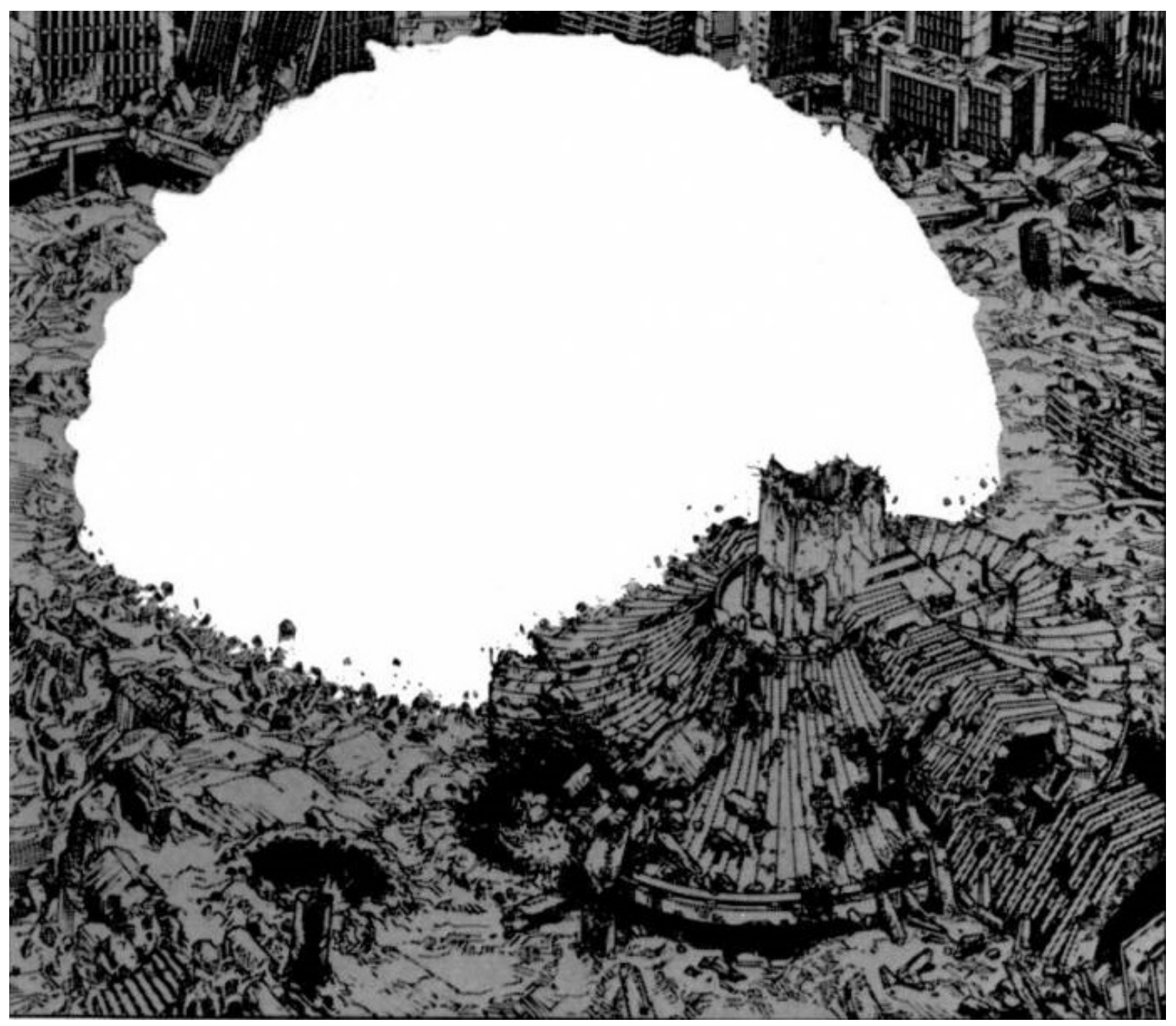

FIG. 14. Ôтомо, K. Op cit. Vol. 6. ${ }^{\circ}$, p. 321.

Es interesante el testimonio de un médico americano que pudo entrar en la ciudad de $\mathrm{Hi}^{-}$ roshima justo después de que cayera la bomba: se trata del doctor Marcel Junod y describe muchos escenarios, pero llama la atención cómo estaba el centro mismo donde cayó la bomba:

El centro de la ciudad era como una mancha blanca, lisa como la palma de la mano. No quedaba nada. Parecían haber desaparecido incluso los rastros de las casas. La mancha blanca se extendía sobre un diámetro de unos dos kilómetros. Estaba bordeada por un cinturón rojo, vestigios de casas quemadas, que se extendía sobre una distancia bastante larga, difícil de evaluar desde el avión, y que cubría casi todo el resto de la ciudad. El espectáculo era simplemente escalofriante. ${ }^{20}$

Allí se resume a cuatro grupos los tipos de víctima: por efecto cástico, quemaduras en general; efecto térmico, muerte por carbonización, se ha estimado que el suelo alcanzó una

20 JunOD, M. El desastre de Hiroshima. p. 296. En https://www.icrc.org/spa/assets/files/other/irrc-230-junod.pdf 
temperatura de 6.000 grados centígrados; efecto mecánico, la fuerza de la onda expansiva, a 1.000 metros de la bomba era de $130 \mathrm{~kg}$. por centímetro cuadrado, de ahí que dependiendo si la persona estaba dentro de una casa o fuera sufría un daño u otro; y por último efecto radiactivo, pues ya hemos apuntado que tanto el uranio como el plutonio eliminan los glóbulos rojos e individuos que aparentemente habían salido indemnes morían a los pocos días de la caída de la bomba.

Todos estos hechos han sido contados de varias formas y utilizando diversas herramientas artísticas. En 1973 el mangaka Keije Nakazawa lo narró en su obra Hadashi no Gen, traducido al castellano como Pies descalzos, que cuenta la historia desde el punto de vista de un niño y, como Akira, mantiene una actitud hostil ante lo estadounidense, como no podía ser de otra manera. Este manga fue censurado por los medios de comunicación occidentales por ser demasiado duro. ${ }^{21} \mathrm{El}$ nombre del protagonista Gen significa "raíz" o "fuente" y como dijo el autor:

Llamé Gen al protagonista con la esperanza en que se convirtiera en una raíz o fuente de fortaleza para una nueva generación de humanos, una que pudiera caminar descalza sobre el suelo carbonizado de Hiroshima, sintiera la tierra bajo sus pies, y tuviera el valor de decir "no" a las armas nucleares. ${ }^{22}$

\section{Otros aspectos de la Guerra}

Es pertinente comentar que Akira es también un niño soldado, no como los que estamos acostumbrados a ver, pero sí es utilizado por los adultos y el aparato militar con fines bélicos, y esto lo convierte a su vez en un arma de destrucción, en su caso, masiva. La diferencia con la realidad es más bien que los niños en la historia de Akira forman parte de un programa oculto, aunque como vamos a ver los niños soldados son "usados" con distintas funciones. Los niños soldados se dan en países donde no hay un ejército regulado profesionalmente y dirigido por unos gobernantes al modo europeo, de hecho la mayoría de países donde se dan son africanos. En el manga, si se utilizan niños, se debe a que el profesor lo que quería obtener era una mutación del sistema nervioso central, para obtener una especie nueva que el gobierno utilizaría como arma de guerra, por tanto la finalidad es una suerte de niño soldado. Graca Machel, autora de un estudio elaborado para Naciones Unidas sobre el impacto de menores en conflictos bélicos, ha calculado que entre el año 1995 y 1996, 250.000 menores sirvieron a ejércitos gubernamentales o fuerzas de oposición. ${ }^{23}$ Tanto el Protocolo adicional de 1997 aplicado a conflictos internos como el Estatuto de Roma firmado en 1998 prohíben el reclutamiento de menores de quince años así como que los dirigentes se abstengan de su inclusión en sus tropas ya que para el Tribunal Penal Internacional constituye un crimen de guerra.

\footnotetext{
${ }^{21}$ Gravett, P. Manga, la era del nuevo cómic. Madrid, H Kliczkowski, 2004.

22 Gravett, P. Op. cit.

${ }^{23}$ Capdevila, G. Derechos humanos: infancia, blanco de las guerras actuales, 2015. En http://www.ipsnoticias. net/1997/12/derechos-humanos-infancia-blanco-de-las-guerras-actuales/
} 

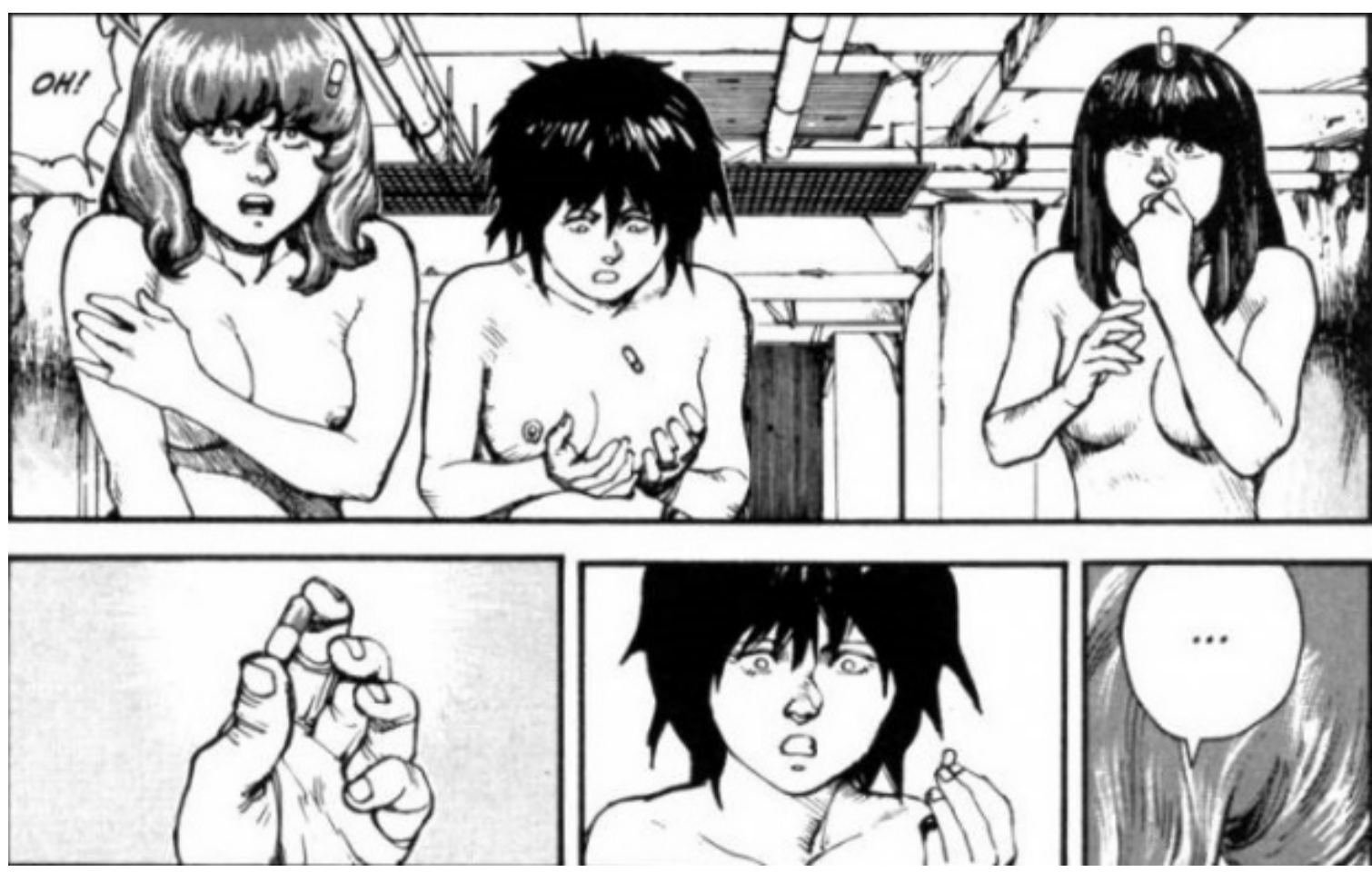

FIG. 15. Ôтомо, K. Op cit.Vol. 4. ${ }^{\circ}$, p. 106.

También hay una relación directa entre la droga y la guerra o más exactamente entre la droga y el acto bélico. Esta situación ocurre también en la actualidad, los dirigentes drogan a los niños soldados para potenciar su estado (llamemos criminal) y para quitarles el temor. Más cruel si cabe es la utilización de niñas soldados como objeto sexual, como avanzadilla de vanguardia, a veces las hacen andar por los campos para detectar minas, o incluso salir al paso para comprobar la presencia de francotiradores o, como hemos visto, con bombas adosadas al cuerpo para crear el pánico entre la multitud, y es obvio que son usadas por el motivo de que las niñas levantan menos sospechas. Por último, esta serie de desgracias no acaba aquí, pues una vez terminado un conflicto bélico, la inclusión de estas niñas en la sociedad es dificilísimo. Para ello se puso en marcha el denominado DDR (Desarme, Desmovilización y Reinserción) con el objetivo que amortiguar el impacto creado por el conflicto. Pensemos que una niña, que sea adicta a las drogas y que posee un trauma de postguerra no es muchas veces bien recibida por su comunidad de origen, por el hecho de que ha sido violada reiteradas veces, ha tenido una descendencia indeseada o ha contraído alguna enfermedad grave, por no hablar de los actos de mutilación, por lo que los miembros de su comunidad pueden reprocharle el hecho de haberse casado con un individuo de una comunidad diferente. Es, como podemos ver, un trauma difícil de superar que marcará el resto de sus días. En el manga Akira encontramos esta figura en la "novia" de Tetsuo, Kaori, y sus compañeras. Se presenta como una chica prisionera, esclava sexual de Tetsuo que finalmente muere en la monstruosidad de su represor (FIGS. 15 y 16).

Por otro lado, algunos gobiernos, han tenido afán de encontrar una sustancia útil para la guerra. Si nos remontamos a mediados del siglo pasado, el caso más sonado fue el llamado $M K-U L T R A$, Fue una operación encubierta llevada a cabo por la Agencia Central de 


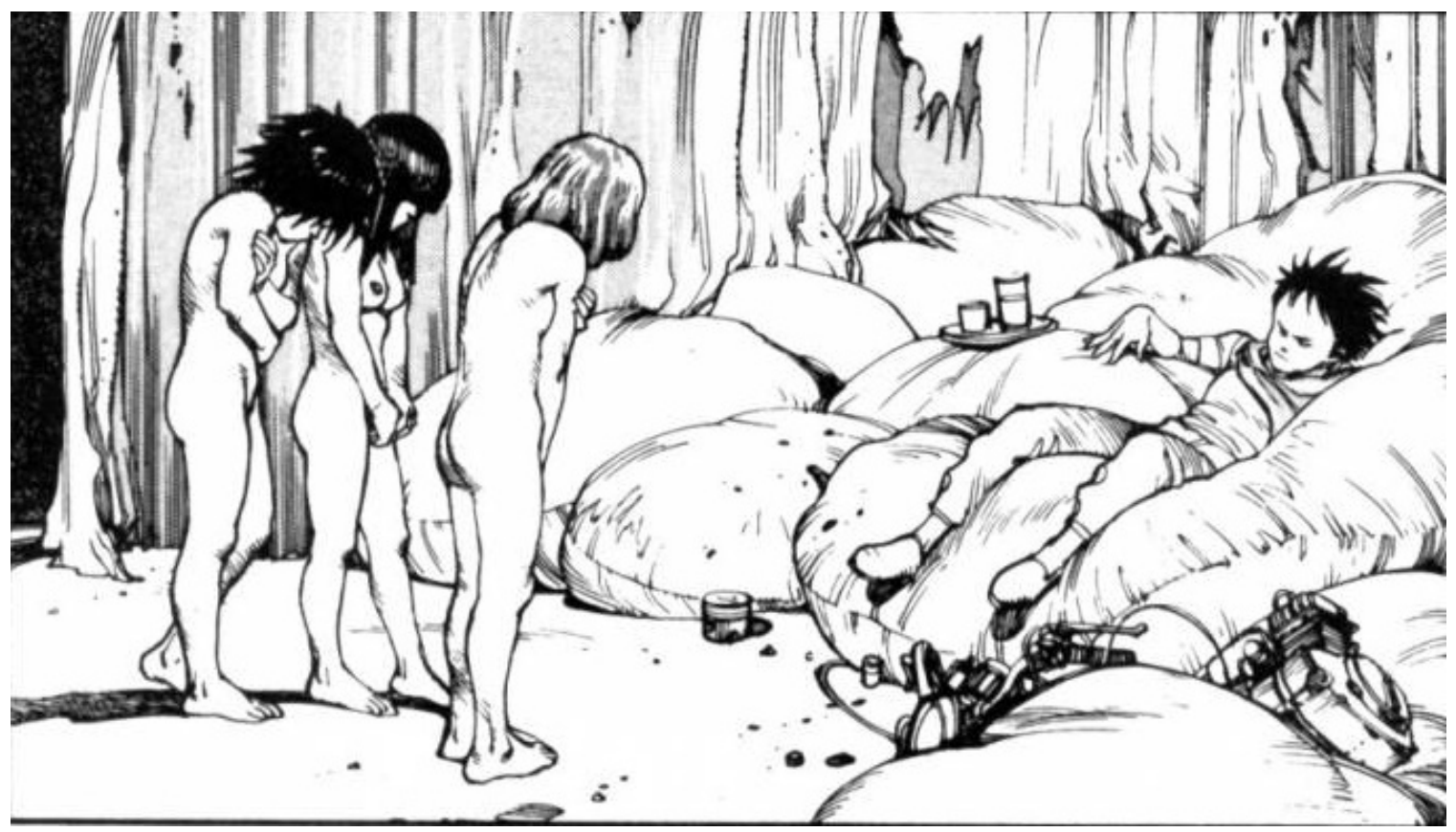

FIG. 16. Ôтомо, K. Opcit. Vol. 4. ${ }^{\circ}$, p. 105.

Inteligencia (CIA) en 1953 y animada por experimentaciones similares en Dachau. La operación fue llevada a cabo por una sección semisecreta conocida como División Química por el farmacólogo S. Gottilieb, que recibió buenas sumas de dinero para adquirir la recién descubierta LSD. Incluso insinuaron a su descubridor, A. Hofmann para que creara una manera de filtrar la droga en la población con el objetivo de crear ataques sorpresas y "producir estados indiscernibles de la insania mental" ${ }^{24}$. Este parece ser el objetivo principal, el de crear un arma no letal pero que asegurara la ventaja y la victoria en un momento dado. Este programa junto con el de Climax de medianoche, que consistía en observar a los clientes de un prostíbulo totalmente vigilado donde las prostitutas vertían, sin que el cliente se percatara, LSD en sus copas y a continuación se observaba el comportamiento de los mismos. Los experimentos fueron un poco más allá llegando a utilizar los alucinógenos en un individuo que, con anestesia local, se le iba preguntando a la misma vez que un cirujano le rebanaba el cerebro con su bisturí. El número de experimentos con humanos derivado de estos programas son varios miles americanos y también laosianos, camboyanos y vietnamitas. El psiquiatra $\mathrm{H}$. Abramson recibió 85.000 dólares para producir los siguientes efectos en sus enemigos: "a. Trastornos de la memoria; b. Desprestigio por conducta aberrante; c. Alteración de pautas sexuales; d. Entrega de información; e. Sugestibilidad; f. Creación de dependencia”. ${ }^{25}$

El proyecto $M k$-Ultra se desvaneció tras otro experimento llevado a cabo por sorpresa por la propia CIA donde un hombre se arrojó al vació tras pensar que se había vuelto loco sin

24 Escohotado, A. Historia General de las drogas. Madrid, Alianza, 1989, p. 611.

25 Ibíd. 
ningún motivo y es que simplemente no sabía que había sido objeto de una "emboscada" entre colegas.

En la misma dirección apuntaba el modelo Stargate, era el proyecto de espionaje psíquico de la CIA desarrollado a partir de los años 70. Este programa estudiaba lo que se ha denominado visión remota o clarividencia. La CIA contaba con personas que decían tener poderes extrasensoriales y clarividentes y eran capaces de describir un lugar a enormes distancias: situación de las bases secretas militares y otros objetivos. El proyecto estaba a cargo de Russel Targ y Harol Puthoff bajo el llamado SCANATE (escaneo por coordenadas). ${ }^{26}$ Aunque no entraremos en este apartado en profundidad, Akira está lleno de alusiones en este sentido. Los poderes que manifiestan los niños con cara de anciano son telequinésicos y también clarividentes. Pero no sólo ellos, sino que encontramos a lo largo del manga otros personajes peculiares, como por ejemplo el hombre pájaro, que con una venda en sus ojos es capaz de ver quien entra en los territorios del Imperio (FIGS. 17 y 18).

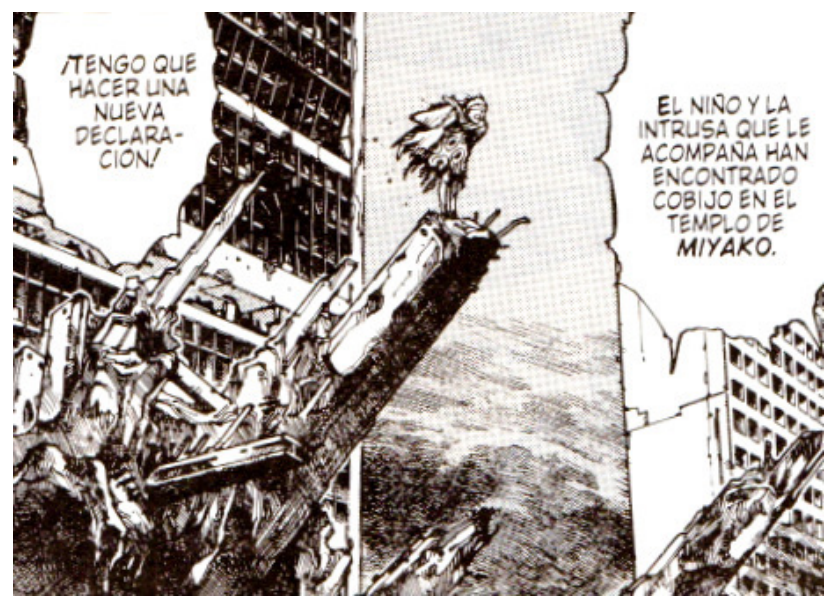

FIG. 17. Ôтомо, K. Op cit. Vol. 4. ${ }^{\circ}$, p. 219.

En el caos que supone la destrucción de la ciudad, Ôtomo ofrece también algunas viñetas al pillaje y a la violación. La prohibición del pillaje ha sido explicitada en distintos convenios. Primero en el de 1907 en La Haya "el saqueo de una ciudad o una localidad, aun cuando haya sido tomada por asalto, está prohibido"27. Dos ideas completamente distintas nos asaltan porque hay que diferenciar distintos tipos de pillaje. El primero sería un pillaje de supervivencia para mantener a las tropas, para lo que se puso en práctica la táctica de la tierra quemada, que consistía en abandonar la población y quemar todas las provisiones con el fin precisamente de no favorecer al enemigo, táctica muy empleada en la Unión Soviética, por lo que las tropas alemanas penetraron rápidamente hacia el interior durante Segunda Guerra Mundial. Esta idea de pillaje podríamos decir que es legítimo pues recompensa los

${ }^{26}$ Retama Yarto, J. Del proyecto MK-Ultra al Stargate: las "guerras mentales" de EE UU. 2014. En http:// contralinea.info/archivo-revista/index.php/2014/08/10/del-proyecto-mk-ultra-al-stargate-las-guerras-mentales-de-estados-unidos/

${ }^{27}$ Convenio IV de la Haya relativo a las leyes y costumbres de la guerra terrestre. 1907 en http://www.cruzroja.es/dih/pdf/Convenio_IV_de_la_Haya_de_1907.pdf 


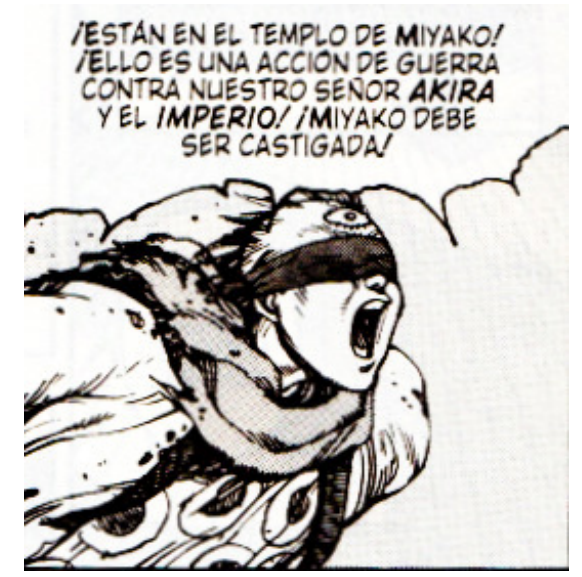

FIG. 18. Ôтомо, K. Opcit. Vol. 4. ${ }^{\circ}$, p. 219.

esfuerzos por la conquista realizada. Y por otro lado encontramos un pillaje de alto standing referido a lo patrimonial: obras de arte en general que constituyen el botín de guerra. Esto último no se da en el manga de Akira. Además está considerado crimen de guerra por el Tribunal Penal Internacional. Su artículo $8 .^{\circ}$ lo especifica en dos ocasiones: 'Destruir o apoderarse de bienes del enemigo, a menos que las necesidades de la guerra lo hagan imperativo" y "Saquear una ciudad o una plaza, incluso cuando es tomada por asalto"28. En Akira el pillaje está retratado por el "ejército" de Akira que va acumulando el material que encuentra a su paso. También otros personajes como el jefe de la banda del payaso que va consiguiendo material con el que construir nuevas motos e incluso consiguió el arma láser que había disparado a Kaneda al principio y no se sabe cómo este personaje lo ha podido recuperar.

Encontramos otras viñetas donde la mujer se presenta como objeto, es el objetivo de un grupo de rebeldes a favor del Imperio de Akira. Como por ejemplo en el volumen 4. ${ }^{\circ}$, páginas 26 y siguientes un grupo se ha cruzado con Kai y la interceptan: "vaya, por fin pillamos una tía. Eh, ricura, mira lo que tengo para ti...”. Y en la página 132 y siguientes otro grupo acorralan a Kai y a Chiyoko mientras estas hablan del destino y el problema que resulta no volver ver a Kaneda, un hombre comenta con los brazos abiertos y cara obscena: "Se acabaron vuestros problemas, ya no tenéis ni destino ni vida." (FIGS. 19, 20 y 21).

Para concluir la cuestión beligerante de Akira digamos que la imaginación va más allá y Ôtomo inventó para el manga un arma que no se ha hecho realidad, afortunadamente. Se trata del satélite SOL-740 y estoy convencido de que no está inventado pero seguro que ha podido ofrecer alguna idea. El satélite SOL es un arma enorme que flota en el espacio y que puede ser controlado desde tierra a través de una "pistola" láser que una vez apuntada hacia su objetivo es disparada y envía las coordenadas al satélite, con lo que SOL puede lanzar un rayo láser de dimensiones descomunales cuyo efecto es, si se puede, la desintegración de la materia, por tanto una vez que alcanza su blanco su destrucción está asegurada. Es precisamente con este rayo con que se le amputa el brazo a Tetsuo (FIGS. 22 y 23).

28 Estatuto de Roma de la Corte Penal Internacional. Bruselas, 17 de julio de 2014, p. 7 en www.ieee.es/.../Internaciona1/2014/CortePenalInternacional_EstatutodeRom... 


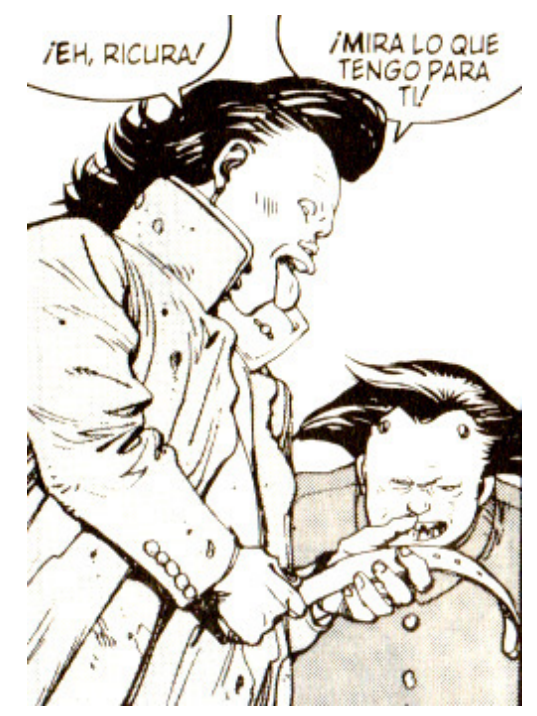

FIG. 19. Ôтомо, K. Op cit. Vol. 4. ${ }^{\circ}$, p. 27.

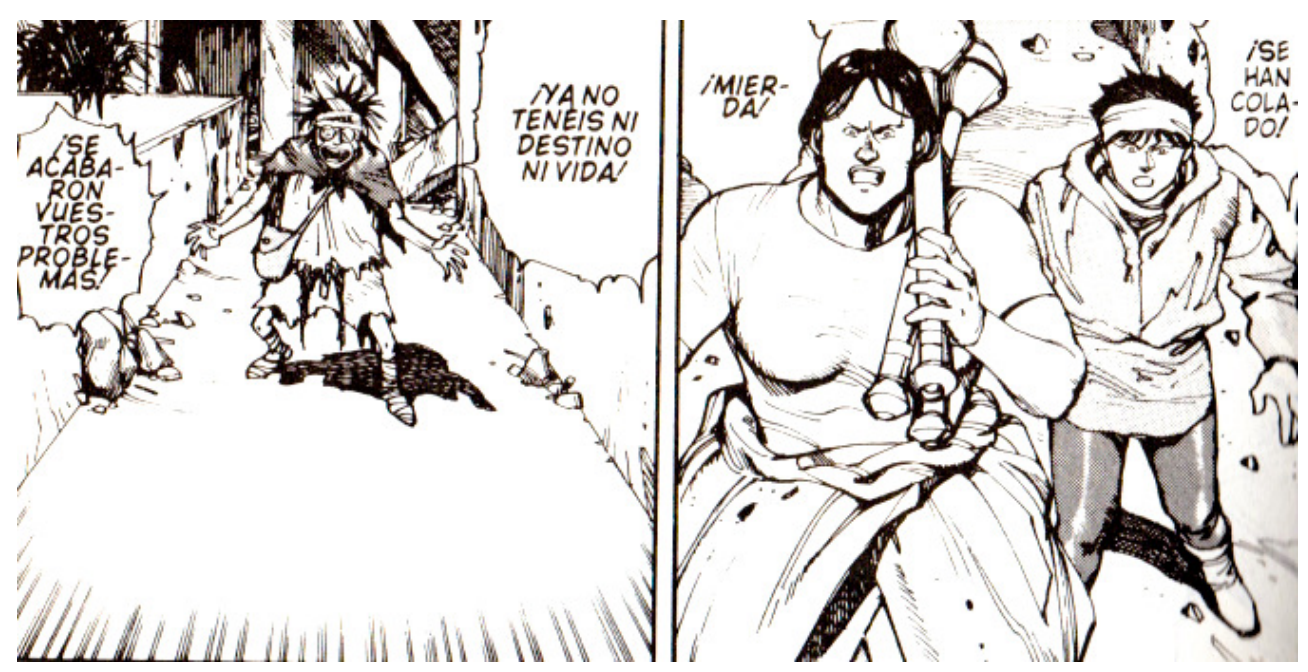

FIG. 20. Ôтомо, K. Op cit. Vol. 4.․ P. 132.
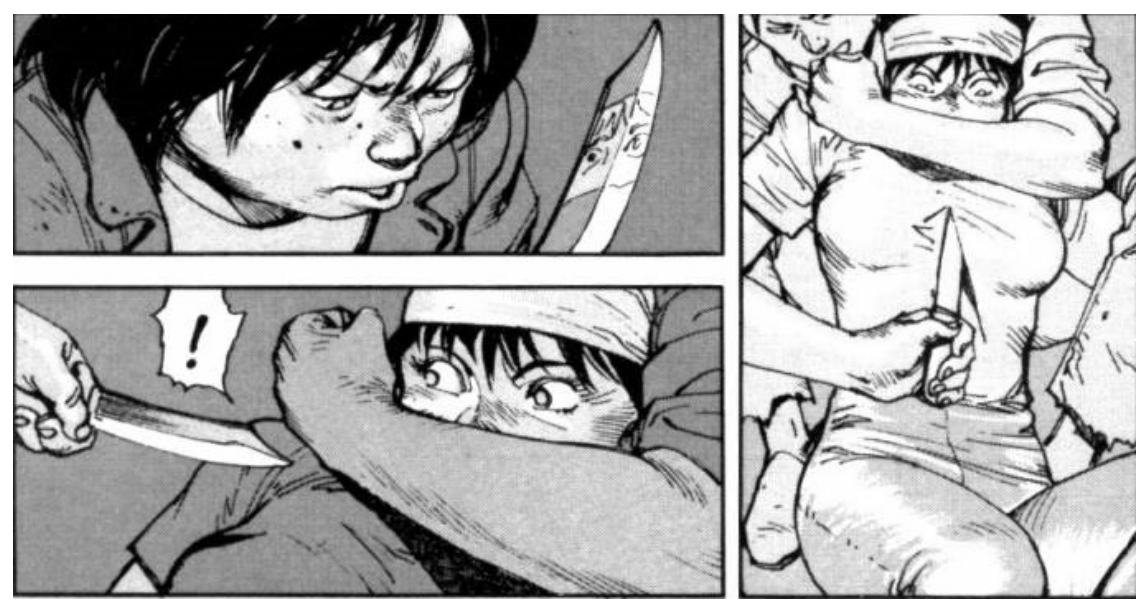

FIG. 21. Оิтомо, K. Op cit. Vol. 4. ${ }^{\circ}$, p. 145. 


\section{Conclusión}

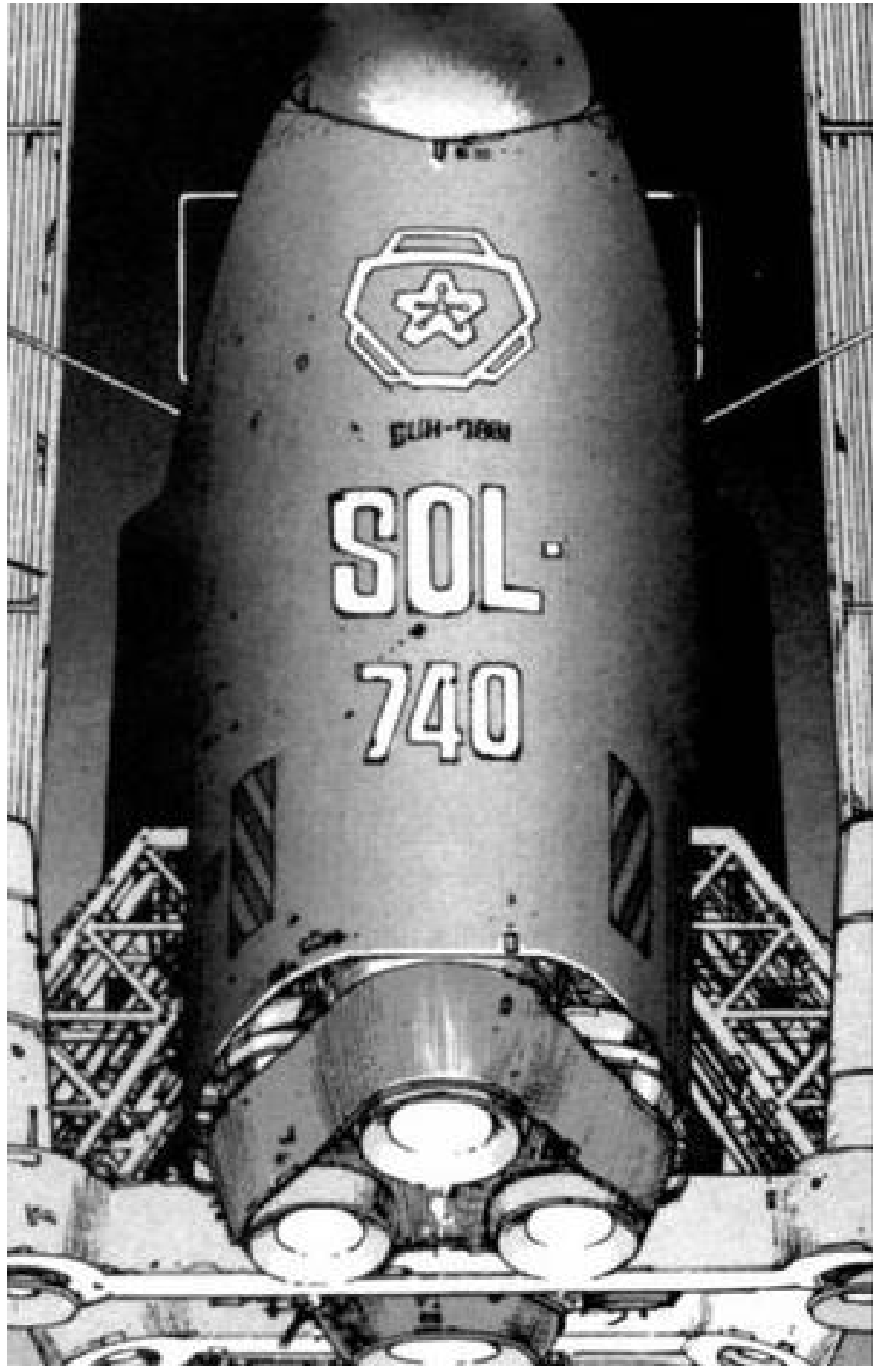

FIG. 22. Оิтомо, K. Op cit. Vol. 4. ${ }^{\circ}$, p. 362.

Japón es un país que quedó estigmatizado por los hechos de la Segunda Guerra Mundial y por las bombas atómicas que fueron lanzadas sobre Hiroshima y Nagasaki el 6 y 9 de agosto de 1945 respectivamente, y ello ha quedado reflejado en la obra de Katsuhiro Ôtomo en general y en Akira en particular pero con un lenguaje paralelo que hemos llamado "apocalíptico", no solo por su vertiente catastrófica sino por su trasfondo verídico, por lo que podríamos hablar de Akira como una obra apocalíptica con un carácter historicista. De este 


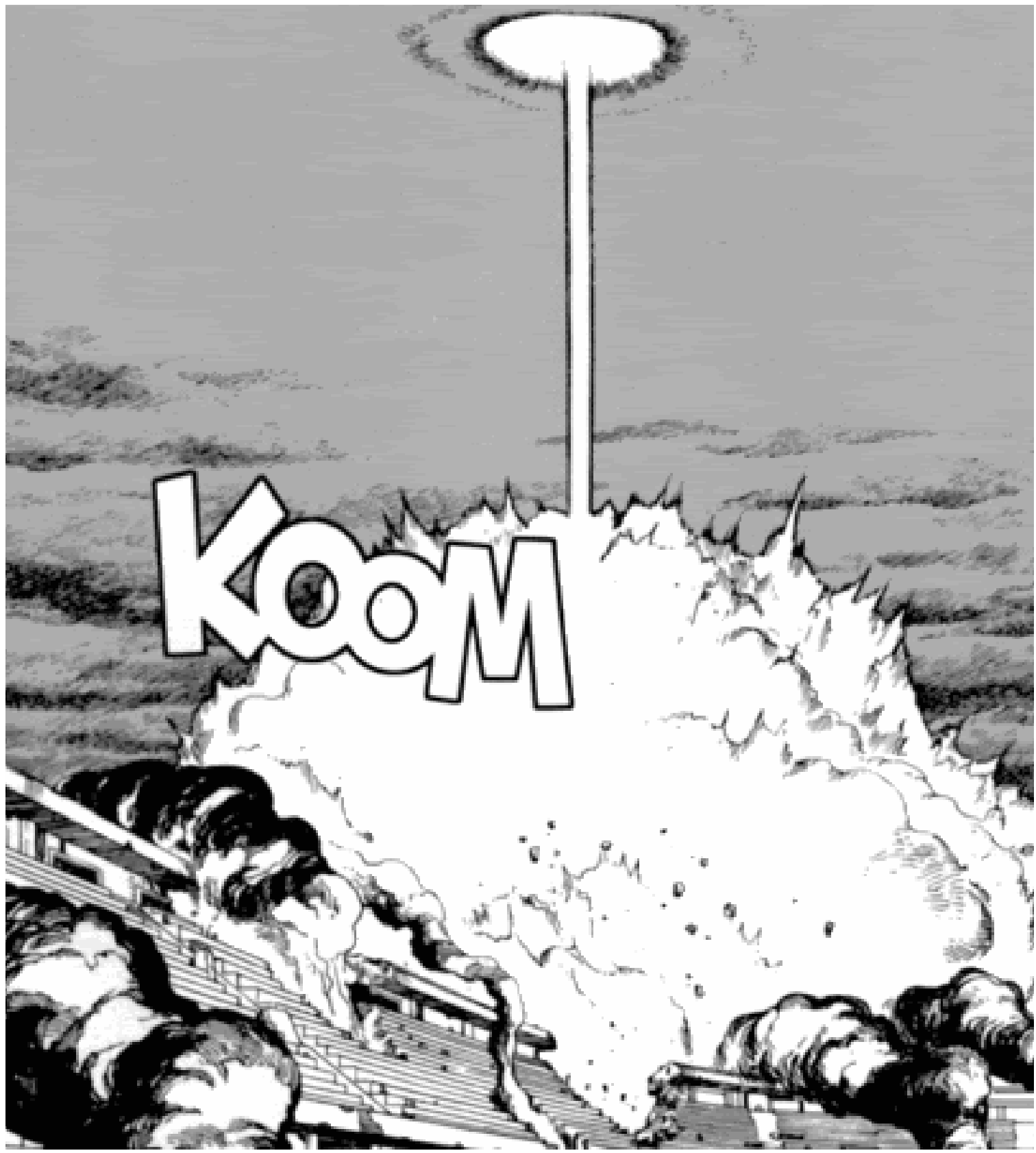

FIG. 23. Ôтомо, K. Op cit. Vol. 6. ${ }^{\circ}$, p. 143.

modo podríamos vincular a su autor a la generación de la llamada "literatura de la bomba atómica” (Genbaku Bungaku) o al menos toma el relevo de la misma, lo que nos hace pensar que las heridas de la guerra no han sido todavía curadas. Por otro lado me gustaría concluir diciendo que Akira no se limita a la cuestión beligerante que hemos tratado en este estudio sino que sus raíces profundizan también en lo que llamamos contracultura, movimiento que surgió en EE UU entorno a los años sesenta y que en Akira aflora en muchas ocasiones, será en otra entrega. 


\section{Referencias}

Bueno Atanze,I.Armasbiológicas:situacióny desarrollo,2012.En www.ieee.es/.../DIEEEO83-2012_ ArmasBiologicas_SituacionRespuesta_I.B (Última revisión, agosto 2015)

Capdevila, G. Derechos humanos: infancia, blanco de las guerras actuales, 2015. En http://www.ipsnoticias.net/1997/12/derechos-humanos-infancia-blanco-de-las-guerras-actuales/ (última revisión, noviembre 2015)

Cid Luca, F. De la literatura (y de otras resultas) que nos trajeron Hiroshima y Nagasaki. 2013. En dialnet.unirioja.es/descarga/articulo/4331008.pdf (Última revisión, agosto 2015)

Chuc, V. Prueba cientifica: ¿̨Necesaria o no?. En www.amcmh.org/PagAMC/medicina/articulospdf/65PruebaCientifica.pdf. (Última revisión, agosto 2015)

Convención sobre la prohibición del desarrollo, la producción y el almacenamiento de armas bacteriológicas (biológicas) y toxínicas y sobre su destrucción. 1972 en http://www.cruzroja.es/dih/ pdf/Convencion_de_1972_sb_armas_biologicas_y_toxinicas.pdf

Convenio IV de la Haya relativo a las leyes y costumbres de la guerra terrestre. $1907 \mathrm{en} \mathrm{http://www.}$ cruzroja.es/dih/pdf/Convenio_IV_de_la_Haya_de_1907.pdf

Escohotado, A. Historia General de las drogas. Madrid, Alianza, 1989.

Fernández Fernández, M. D. El comercio exterior y la no proliferación de las armas químicas y biológicas, 2002. En dialnet.unirioja.es/servlet/articulo?codigo=236237

Gutman, R. y Rieff, D. (Coord.) Crimenes de Guerra, lo que debemos saber. Barcelona, Debate, 2003.

HARris H., S. Japanese biomedical experimentation during the world-war-ii era. En www.laguardia. cuny.edu/maus/files/Ethics-ch-16.pdf (Última revisión, agosto 2015)

Herradon Ameal, O. La Orden Negra. El ejército pagano del III Reich. Barcelona, Edaf, 2011.

Hidalgo García, M. M. La $3^{\circ}$ conferencia de revisión de la convención para la probibición de armas quimicas, 2013. En www.ieee.es/.../2013/DIEEEI15-2015_ConferenciaRevisionConvencio (Ú1tima revisión, agosto 2015)

Junod, M. El desastre de Hiroshima. En https://www.icrc.org/spa/assets/files/other/irrc-230-junod. pdf (última revisión, agosto 2015)

Kenzaburo, O. Cuadernos de Hiroshima. Barcelona, Anagrama, 2011.

López Aguilera, E., Prado Rodríguez, D. y Sastre, M. A. Manhattan project: «el papel de los cientificos en el desarrollo de la bomba atómica», 1999. En http://upcommons.upc.edu/bitstream/ handle/2099/9730/Article019.pdf;jsessionid=D18089D82500FF1A80E53DA6B5BF1FF7?sequence=1ESILldianres de la ETSETB (Última revisión, agosto 2015)

Machín, N. Las armas biológicas. Perspectivas de futuro, 2014. En revistas.ucm.es/index.php/UNIS/ article/viewFile/46428/4362 (Última revisión, agosto 2015)

Mendoza, Diego H. De. Entre el pacifismo y la energía nuclear (1930-1955), 2007. En http://arxiv. org/ftp/arxiv/papers/0706/0706.0995.pdf (Última revisión, agosto 2015)

Ôтомо, K. Akira. Barcelona, Ediciones B, 1999.

Palacián de Inza, B. El creciente uso de los niños soldados, 2015. En www.ieee.es/Galerias/.../2015/ DIEEEA12-2015_NinosSoldado_BPI.pdf (Última revisión, agosto 2015) 
Pigrau Solé, A. El empleo de armas nucleares ante el derecho internacional humanitario. En http:// www.frdelpino.es/wp-content/uploads/2014/10/en_6-Antoni-PIGRAU-SOL\%C3\%89.pdf. (última revisión, noviembre 2015)

Retama Yarto, J. Del proyecto MK-Ultra al Stargate: las "guerras mentales" de EE UU. 2014. En http://contralinea.info/archivo-revista/index.php/2014/08/10/del-proyecto-mk-ultra-al-stargate-las-guerras-mentales-de-estados-unidos/(Ultima revisión, agosto 2015)

Veracity, D. Experimentos médicos en seres humanos... en los EEUU. 2006. Del sitio web Naturalnews. Traducción de Adela Kauffman en http://www.bibliotecapleyades.net/ciencia/ciencia_industryweapons178.htm. (Última revisión noviembre 2015)

VVAA. Convenio de Ginebra del 22 de agosto de 1864 para el mejoramiento de la suerte de los militares beridos en los ejércitos en campaña. Recopilado por la Cátedra de Estudios Internacionales/Nazioarteko Ikasketen Cátedra Universidad del País Vasco-Euskal Herriko Unibertsitatea UPVEHU (Última revisión, agosto 2015)

VVAA. Estatuto de Roma de la Corte Penal Internacional. Bruselas, 2014. En www.ieee.es/.../Internacional/2014/CortePenalInternacional_EstatutodeRom... (Última revisión, agosto 2015)

VVAA. Protocolos Adicionales a los Convenios de Ginebra del 12 de agosto de 1949. Comité internacional de la Cruz Roja. En https://www.icrc.org/spa/resources/documents/publication/p0321. htm (Última revisión, agosto 2015)

VVAA. Hoja informativa Resumen de los Convenios de Ginebra de 1949 y sus Protocolos Adicionales. En http://es.scribd.com/doc/146969296/Convenios-de-Ginebra\#scribd (Última revisión, agosto 2015) 